\title{
Taxonomic updates and descriptions of four new Lophopini planthopper species (Hemiptera, Fulgoroidea, Lophopidae) from Yunnan province, South China
}

\author{
Menglin WANG ${ }^{1}$, Adeline SOULIER-PERKINS ${ }^{2}$, Yinglun WANG ${ }^{3, *} \&$ Thierry BOURGOIN ${ }^{4, *}$ \\ ${ }^{1,3}$ Key Laboratory of Plant Protection Resources and Pest Management of the Ministry of Education; \\ Entomological Museum, Northwest A\&F University, Yangling, Shaanxi 712100, China. \\ ${ }^{2}$ Mécanismes adaptatifs et évolution, MECADEV-UMR 7179 MNHN-CNRS, Muséum national \\ d'Histoire naturelle, 57 rue Cuvier, CP 50, F-75005 Paris, France. \\ ${ }^{1,4}$ Institut de Systématique, Évolution, Biodiversité, ISYEB-UMR 7205 MNHN-CNRS-UPMC-EPHE, \\ Muséum national d'Histoire naturelle, Sorbonne Universités, 57 rue Cuvier, CP 50, F-75005 Paris, France.
}

\author{
*Co-corresponding authors: bourgoin@mnhn.fr; yinglunw@nwsuaf.edu.cn \\ 1Email: wangmenglin123@,126.com \\ ${ }^{2}$ Email: soulier@mnhn.fr \\ ${ }^{1}$ urn:Isid:zoobank.org:author:D1E5A9BD-C0EF-4022-A18F-6CD9416F1C62 \\ ${ }^{2}$ urn:1sid:zoobank.org:author:780D689B-DAD3-4115-9C34-97C27B580EB9 \\ ${ }^{3}$ urn:lsid:zoobank.org:author:9CEA8D88-C333-412A-ACAC-D48209BD97C7 \\ ${ }^{4}$ urn:1sid:zoobank.org:author:54BA483C-CAFE-4C52-8321-7371A1A97ACA
}

\begin{abstract}
Taxonomic updates and descriptions of four new species from Yunnan, China are provided: three new species in the genus Pitambara Distant, 1906: P. triremiprocta Wang \& Soulier-Perkins, sp. nov., P. impudica Wang \& Bourgoin, sp. nov., P. tricorne Wang \& Wang, sp. nov., and one new species in the genus Serida Walker, 1857: Serida parenthesisflexuosa Wang \& Soulier-Perkins, sp. nov. A new identification key to Pitambara species is provided, as well as to the species of the genus Lacusa Stål, 1862. Lacusa yunnanensis Chou \& Huang, 1985 stat. rev. is not considered as a synonym of the species L. fuscofasciata (Stål, 1854) anymore and Lacusa orientalis (Liang, 2000) is transferred to the genus Acothrura Melichar, 1915 as Acothrura orientalis (Liang, 2000) comb. nov.
\end{abstract}

Keywords. Taxonomy, new taxa, Pitambara, Serida, Lacusa.

Wang M., Soulier-Perkins A., Wang Y. \& Bourgoin T. 2016. Taxonomic updates and descriptions of four new Lophopini planthopper species (Hemiptera, Fulgoroidea, Lophopidae) from Yunnan province, South China. European Journal of Taxonomy 185: 1-25. http://dx.doi.org/10.5852/ejt.2016.185

\section{Introduction}

The planthopper family Lophopidae Stål, 1866 is a small family, presently including 47 genera (5 of which are fossil) and 149 species (Bourgoin 2016). A cladistic analysis performed by Soulier-Perkins (2001) showed that four main monophyletic lineages could be identified: Carrionia ${ }^{+}, \mathrm{Makota}^{+}, \mathrm{Bisma}^{+}$and Sarebasa $^{+}$. In 2014, Emeljanov redefined the Lophopidae subfamilies and added two tribes (Emeljanov 
Table 1. Known Lophopidae species in China.

\begin{tabular}{|c|c|c|}
\hline Genera & Species & Locations in China \\
\hline \multirow[t]{2}{*}{ Acothrura Melichar, 1915} & Acothrura fucizona Wang, Zhou \& Yuan, 2000 & Yunnan \\
\hline & Acothrura impunctata (Jacobi, 1905) & Yunnan \\
\hline Bisma Distant, 1906 & Bisma longicephala Liang, 2000 & Hainan \\
\hline Elasmoscelis Spinola, 1839 & Elasmoscelis perforata Walker, 1862 & $\begin{array}{l}\text { Guangdong, Hainan, } \\
\text { Taiwan }\end{array}$ \\
\hline \multirow[t]{4}{*}{ Lacusa Stål, 1862} & Lacusa digitata Xing \& Chen, 2014 & Yunnan \\
\hline & Lacusa fuscofasciata (Stål, 1854) & $\begin{array}{l}\text { Guizhou, Guangdong, } \\
\text { Hainan, Yunnan }\end{array}$ \\
\hline & Lacusa orientalia Liang, 2000 & Yunnan \\
\hline & Lacusa producta Xing \& Chen, 2014 & Yunnan \\
\hline Lophops Spinola, 1839 & Lophops carinata (Kirby, 1891) & Hainan, Taiwan \\
\hline Paracorethrura Melichar, 1915 & Paracorethrura iocnemis (Jacobi, 1905) & Guangxi \\
\hline \multirow[t]{2}{*}{ Pitambara Distant, 1906} & Pitambara dawnana Distant, 1912 & Yunnan \\
\hline & Pitambara nigrofuscata Liang, 2000 & Yunnan \\
\hline Podoschtroumpfa Soulier-Perkins, 1998 & Podoschtroumpfa rubrolineata Liang, 2000 & Yunnan \\
\hline \multirow[t]{2}{*}{ Pyrilla Stål, 1859} & Pyrilla perpusilla (Walker, 1851) & Yunnan \\
\hline & Pyrilla sinica Liang, 1997 & $\begin{array}{l}\text { Fujian, Jiangxi, Hainan, } \\
\text { Guangxi, Yunnan }\end{array}$ \\
\hline Serida Walker, 1857 & $\begin{array}{l}\text { Serida elasmoscelis (Jacobi, 1944) } \\
\text { Serida latens Walker, } 1857\end{array}$ & $\begin{array}{l}\text { Fujian, Hainan, Jiangxi } \\
\text { Fujian }\end{array}$ \\
\hline
\end{tabular}

2014). The Lophopini Stål, 1866, sensu Emeljanov, contains the same genera as in Sarebasa ${ }^{+}$, plus Katoma Baker, 1925, which was absent in Soulier-Perkins's phylogenetic analysis (2001), but minus Elasmoscelis Spinola, 1839, which was placed in the Elasmoscelini tribe. Sarebasa ${ }^{+}$is widely distributed, from Africa to the Solomon Islands and from China to Australia. Its distribution remains patchy and, since many taxa show great abilities to disperse (Soulier-Perkins 2000), it remains difficult to determine the biogeographic origin of this group. However, Sarebasa ${ }^{+}$remains the group with the most affinities with continental land masses, particularly Southeast Asia.

Eleven genera and 18 species of Lophopidae are actually found in China, but only in its oriental region (Table 1). Liang (1996) studied the Chinese lophopids and provided a first checklist for the country, containing 7 genera and 8 species. The following year he added a new species (Liang 1997), then three new ones in 2000 (Liang 2000). In the same year, Wang et al. (2000) described one new species and registered Acothrura impunctata (Jacobi, 1905) as new for China. Later, Podoschtroumpfa rubrolineata Liang, 2000 was registered as new for China by Wang \& Wang (2012) and, finally, two new species were added by Xing \& Chen (2014).

In the present paper, the checklist for China is enriched by four new species that we describe and we review the distribution of Chinese Lophopidae together with several necessary taxonomic adjustments in this family.

\section{Material and methods}

The specimens were prepared after softening for 12 hours in a cylinder glass with humid conditions. Subsequently, the abdomen of the specimens was separated from the body, then boiled in a $10 \%$ $\mathrm{KOH}$ solution for 5 to 10 minutes. When needed, some drops of blue paragon were added for a better observation of the ectodermic genital ducts. The final observation was done in glycerin. Photographs of the specimens were taken with a Leica DFC camera attached to a Leica M205A stereo microscope and further processed with LAS V3.7 software. Terminology follows Bourgoin (1988) and SoulierPerkins $(1998,2001)$ for male genitalia and Bourgoin et al. (2015) for forewing venation. For each new described species, two authors are selected for the authorship: the first author of the article Wang M.L. followed alternatively by one of the three other authors. 


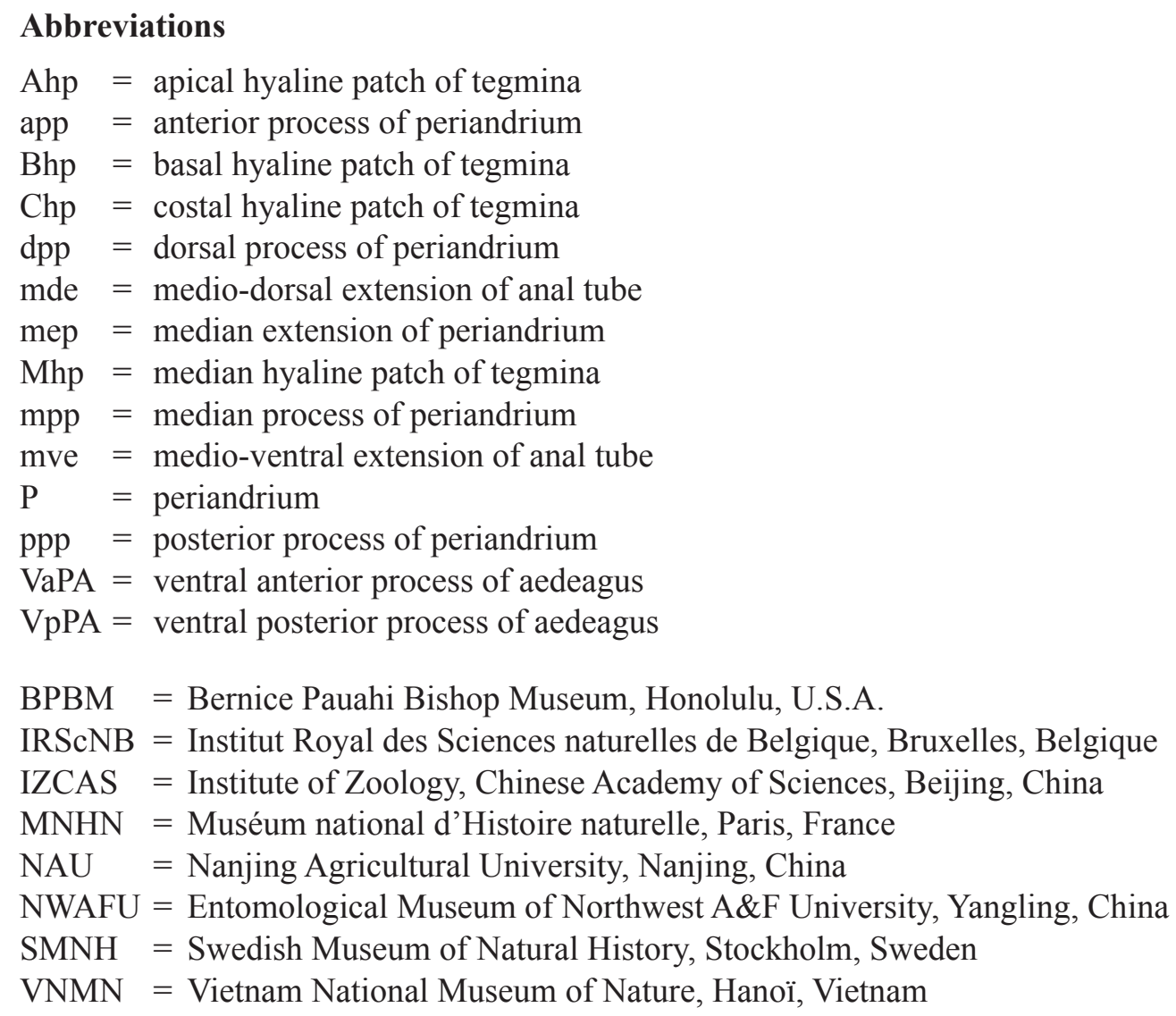

\section{Results}

Class Hexapoda Blainville, 1816

Order Hemiptera Linnaeus, 1758

Suborder Auchenorrhyncha Duméril, 1806

Infraorder Fulgoromorpha Evans, 1946

Superfamily Fulgoroidea Latreille, 1807

Family Lophopidae Stål, 1866

Subfamily Lophopinae Stål, 1866

Tribe Lophopini Stål, 1866

Genus Pitambara Distant, 1906

Pitambara Distant, 1906: 319.

Pitambara-Melichar 1915: 361. — Liang 2000: 291.

\section{Type species}

Elasmoscelis radians Kirby, 1891, designated by subsequent designation of Melichar (1915: 361).

\section{Redescription}

Relatively small taxon, length 7.0-8.5 mm. Head including eyes narrower than pronotum. Vertex moderately long, about 1.0-1.5 times longer than broad, slightly produced forward in front of eyes or at level of anterior margin of eyes; anterior and lateral margins carinated and elevated, anterior margin slightly convex or nearly straight, posterior margin concave. Compound eyes large. Ocelli present; genal 
and ocelar carinae absent; foramen of the antenna not touching compound eye. Antennae with scape very small and short; pedicel oblong. Frons much longer than broad in ventral view, margins carinated, lateral margins moderately ampliated basally, sublateral carinae well marked and elevated, not reaching frontoclypeal suture, but joining each other anteriorly and reaching vertex margin by forming short common stem, median area depressed, median carina, if present, very weak. Clypeus thick, elevated medially, median carina well developed. Labium short, not reaching hind coxae; apical segment extremely short. Pronotum shorter and broader than vertex, tricarinate, anterior margin convex, posterior margin nearly straight, dorso-lateral angle oblique, median area small and narrow, lateral carinae fused at anterior margin. Mesonotum large, tricarinate. Tegmina relatively short and broad, apical margin rounded, claval margin slightly ampliated beyond clavus; costal area broad, or narrow near base and broadening from base to apex, with many transverse parallel veins inside; subapical line in apical part generally observable, veins Pcu and A1 fused at middle of clavus. Hindwings broader than tegmina; anal lobe developed, without transverse veins on apical area. Fore and median femora and tibiae flattened. Hind tibiae somewhat dilated at apex, with 2 spines on lateral margin and over 30 small spines organised on 3 to 5 rows in apical part. First metathoracic tarsal segment incrassate, longer than cumulative length of next two segments, bearing a pad of microsetae ventrally, one apical spine on each side plus a few additional small ones.

\section{Key to the species of Pitambara Distant, 1906}

1. Tegmina with a costal hyaline patch (Figs 1, 5, 16, 27, Chp)................................................... 2

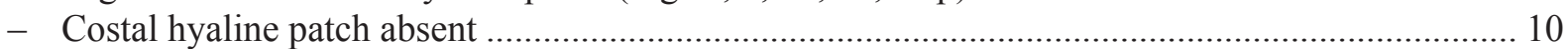

2. Apical hyaline patch of tegmina without any stripe inside

P. dawnana Distant, 1912

- Apical hyaline patch of tegmina with a sinuate stripe inside (Figs 3, 5, 16, 27, Ahp) 3
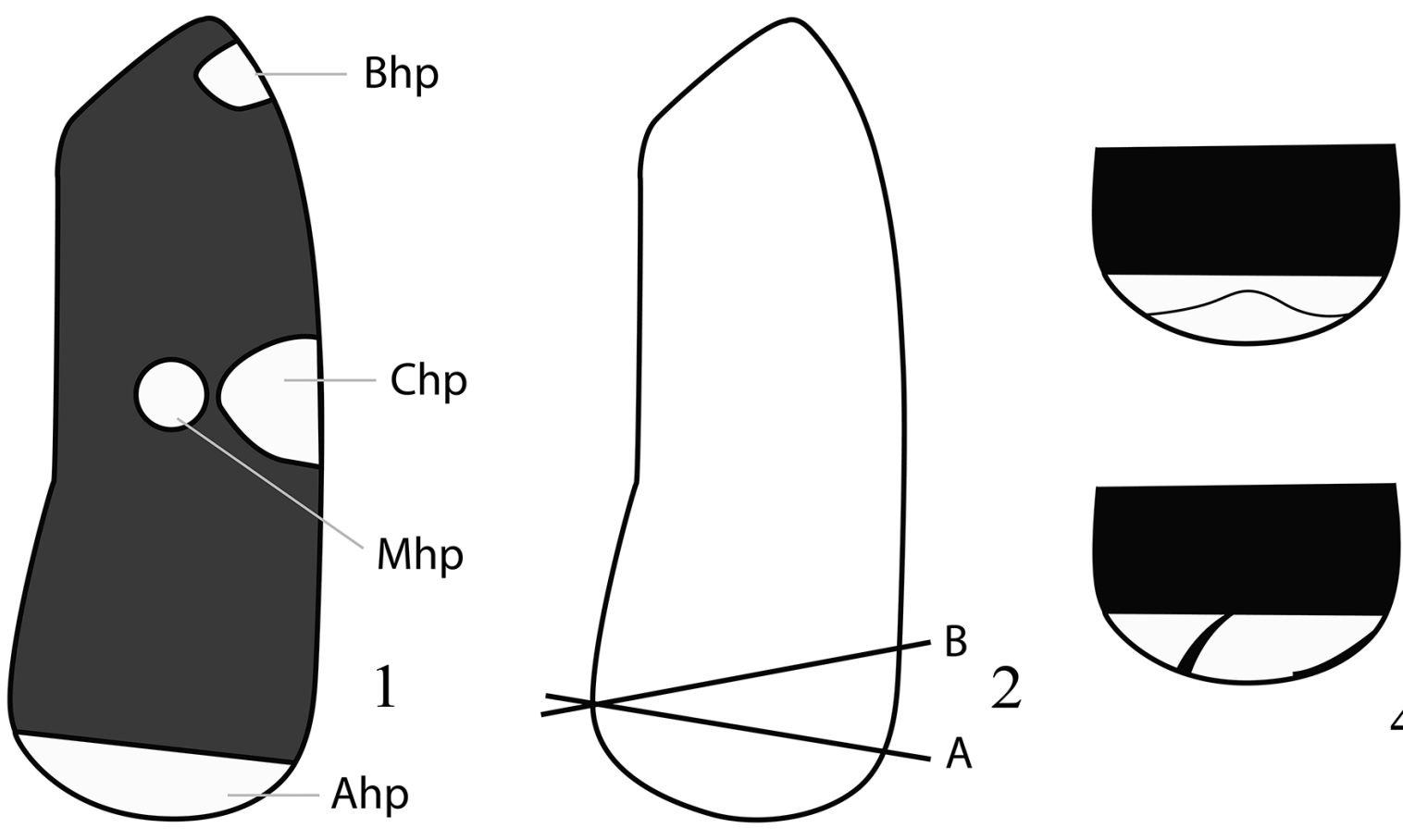

Figs 1-4. Schematic patterns on tegmina of Pitambara. 1. Placement of the different possible hyaline patches. 2. Shape of the apical hyaline patch delineated according to the A or B line. 3-4. Apical hyaline patch with sinuate ornamentation (3) or a thick stripe reaching the apical margin of tegmina (4). 
3. Apical hyaline patch of tegmina delineated by the B line (Fig. 2)

4. Frons with the area between sublateral carinae reddish

- Frons with the area between sublateral carinae not reddish

5. Vertex with three longitudinal stripes (Figs 8, 19, 30)

- Vertex without stripe.

6. Frons white, sublateral carinae brown, with two brown bands near lateral angles of frons (Fig. 31)... P. tricorne Wang \& Wang, sp. nov.

- Coloration of frons and carinae different.

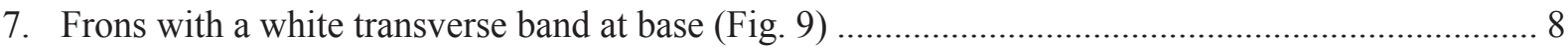

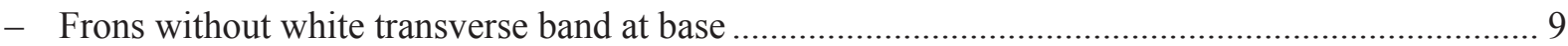

8. Longitudinal stripes on vertex extremely slim

- Longitudinal stripes on vertex thick (Fig. 8) ....... P. triremiprocta Wang \& Soulier-Perkins, sp. nov.

9. Tegmina with a basal hyaline patch (Figs 1, 16, Bhp)..........P. impudica Wang \& Bourgoin, sp. nov.

- Basal hyaline patch absent...............................................................P. tonkinensis Lallemand, 1942

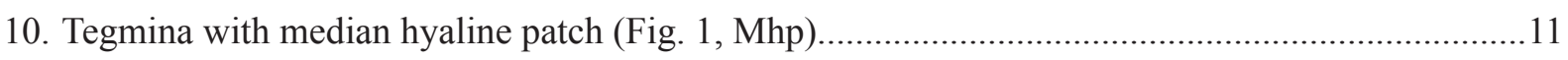

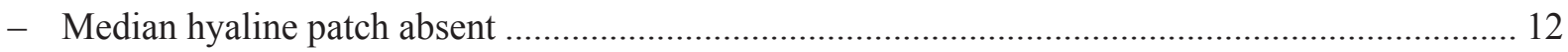

11. Frons reddish in median and lateral part....................................................... tagalica (Stål, 1854)

- Frons yellowish, without any red colour .................................................... undulata Distant, 1906

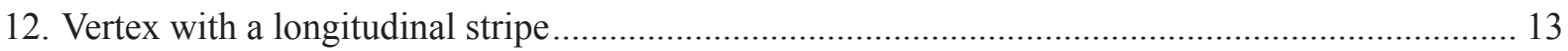

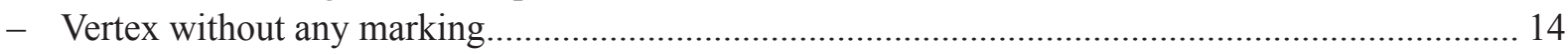

13. Apical hyaline patch of tegmina containing a thick stripe reaching the apical margin of tegmina by one end (Fig. 4); sublateral carinae of frons brownish

P. nigrofuscata Liang, 2000

- Apical hyaline patch of tegmina containing a slim sinuate brownish line the apical margin of tegmina by both of its ends (Fig. 3); sublateral carinae of frons yellowish.

P. sinuata Distant, 1906

14. Tegmina mostly brownish, some discolorations are present on the basal and claval area; fore femora with basal half black, apical half yellowish with two fuscous stripes

P. radians (Kirby, 1891)

- Tegmina mostly black without any discoloration within the medo-basal and claval area; fore femora yellowish with several fuscous transverse stripes

P. borneensis Baker, 1925

Pitambara triremiprocta Wang \& Soulier-Perkins, sp. nov. urn:Isid:zoobank.org:act:E5848886-C6B5-45C0-BB0F-61137185BB72

Figs 5-15, 38-39

\section{Diagnosis}

Within the Pitambara species presenting a costal hyaline patch on the tegmina (Fig. 1), P. triremiprocta is the only one for which this patch is roughly triangular, with a very large base along the costal margin and its tip reaching the level of $\mathrm{CuA}$, and with an apical hyaline patch having a brown sinuate stripe inside (Fig. 5). 


\section{Etymology}

Free arrangement between the words "trireme" and "proctodeum" since the apex of the anal tube is shaped like the bow of ancient Mediterranean warship.

\section{Type material}

\section{Holotype}

CHINA: ồ, Menglun, Yunnan Province, 570 m, 11 Dec. 1999, coll. Daozheng Qin (NWAFU).

\section{Paratypes}

CHINA: 1 , primeval forest, Menglun, Yunnan Province, 8 Jun. 1974, collector unknown (NWAFU); 1 , Jinghong, Yunnan Province, Aug. 1975, coll. Ding Jinhua (NAU).

\section{Description}

Length, male (including tegmina) $(\mathrm{n}=1): 8.2 \mathrm{~mm}$, female (including tegmina) $(\mathrm{n}=2): 8.2-8.5 \mathrm{~mm}$.

Vertex 1.3 times longer in midline than broad at base, anterior margin V-shaped well marked, lateral margins elevated and posterior margin largely rounded, with its most anterior point being at the level of the middle of the compound eyes (Fig. 8). Frons 1.5 times longer in midline than its widest part (Fig. 9), slender median carina present. Pronotum 4.1 times broader at widest part than long in midline (Fig. 8). Mesonotum 1.4 times broader at widest part than long in midline (Fig. 8).

\section{Coloration}

Vertex pale tawny, with three fuscous longitudinal stripes, anterior and lateral margins black (Figs 5, 8). Eyes brownish ochraceous (Fig. 8). Frons pale tawny, with a broad white transverse band at base, sublateral carinae ochraceous (Fig. 9). Clypeus yellow, with apical part dark brown (Fig. 9). Gena greyish white, with one fuscous transverse stripe crossing ocellus (Fig. 7). Ocelli brown. Pronotum tawny, with median and lateral carinae yellow; the median area surrounded by lateral carinae brown (Fig. 8). Mesonotum black, median carina black, lateral carinae with upper half black and lower half tawny, lateral area dark brown mixed with tawny (Fig. 8). Tegmina dark brown; costal margin with several short fuscous transverse stripes near base, one very large white triangular marking at middle extending to outer margin of clavus, sparsely diffuse with short fuscous stripes inside; apical part of tegmina with two small irregular white markings along costal margin, and white at apex, with one fuscous sinuate stripe inside (Fig. 5). Hindwings pale brown. Legs pale tawny, fore and middle femora and tibiae diffused with fuscous transverse stripes.

\section{Male terminalia}

In lateral view, pygofer higher than wide, with dorsal margin deeply sloping posteriorly for the first half and slightly sloping for the second half, postero-dorsal angle rounded (Fig. 10); dorsal margin shorter than ventral margin; posterior margin with a deep cut out on its $1 / 3$ upper part. In ventral view, pygofer posterior margin almost straight, with the exception of lateral angles rounded (Fig. 11). Anal tube in dorsal view wider than long, with apical part slightly convex and lateral margins oblique, dorso-lateral angles obviously prominent at each side (Fig. 13), in lateral view anal tube prolonged posteriorly beyond the anal opening point by a medio-ventral extension gradually tapering to apex (Fig. 10). Gonostylus approximately as high as broad; dorsal margin concave near middle, with a small hook-like process directed postero-ventrally; ventral margin obliquely rounded (Figs 10, 14). Periandrium in lateral view rounded apically, bearing on each side a fold rounded apically as well, but bearing a series of very small teeth (Figs 15, 38). Aedeagus bearing a pair of ventral processes oriented anteriorly (Figs 15, 39); in ventral view, apex of periandrium with a clear ditch; ventral process of aedeagus zigzag shaped (Fig. 12). 

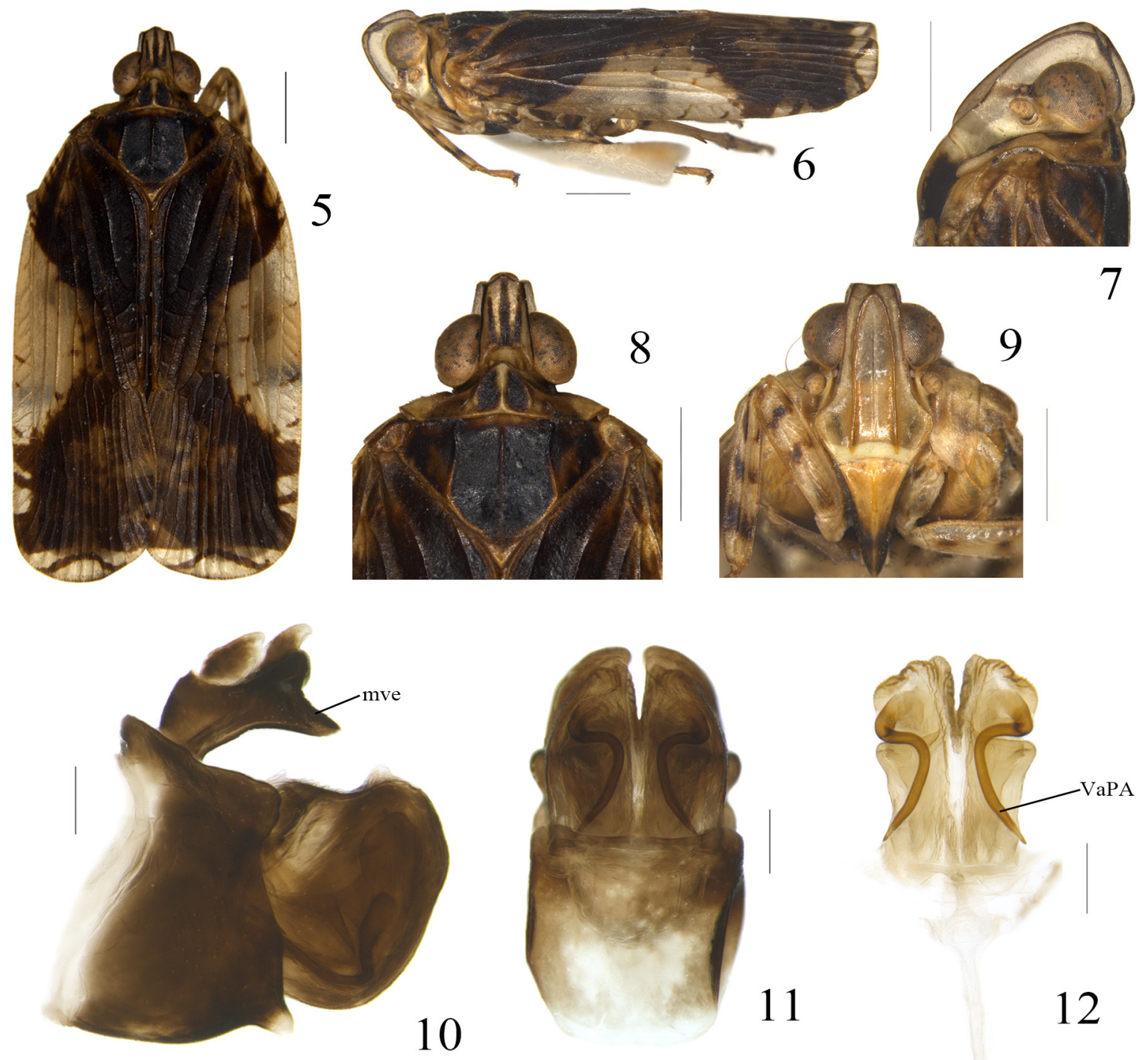

12
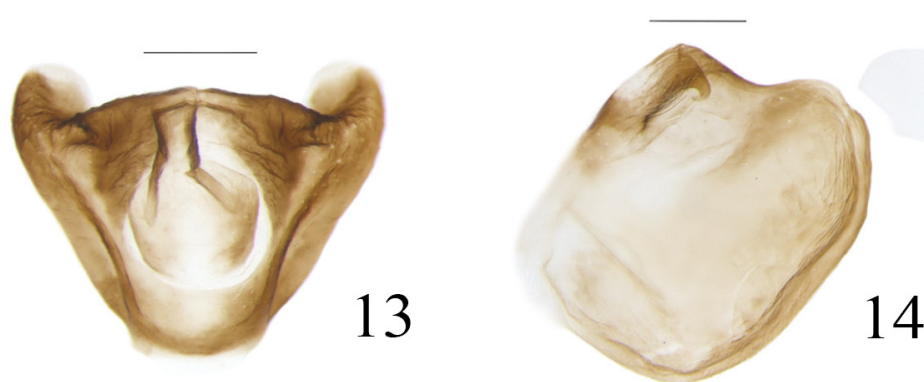

14

Figs 5-15. Pitambara triremiprocta Wang \& Soulier-Perkins, sp. nov., holotype, $ð$. 5. Habitus, dorsal view. 6. Habitus, lateral view. 7. Head, lateral view. 8. Head and thorax, dorsal view. 9. Frons and clypeus. 10. Male terminalia, lateral view. 11. Male terminalia, ventral view. 12. Phallic complex, ventral view. 13. Anal tube, dorsal view. 14. Gonostylus, lateral view. 15. Phallic complex and tectiform structure, lateral view. Scale bars: $5-9=1 \mathrm{~mm}: 10-15=0.2 \mathrm{~mm}$. 
Pitambara impudica Wang \& Bourgoin, sp. nov. urn:Isid:zoobank.org:act:0B90E5F8-2ADC-4DF5-8ECA-BD05CC6A7605

Figs 16-26, 40-41

\section{Diagnosis}

This species can be distinguished from all other Pitambara species by the presence on its tegmina of a basal hyaline patch and a costal hyaline patch (Fig. 1) both roughly rectangular (Fig. 16).

\section{Etymology}

The Latin name impudica refers to the shape of the anal tube in dorsal view (Fig. 24), similar to insulting digitibus impudicus as called in the ancient Rome.

\section{Type material}

\section{Holotype}

CHINA: Ô, Menglun, Yunnan Province, 25 May 1991, coll. Yinglun Wang \& Wanzhi Cai (NWAFU).

\section{Paratypes}

CHINA: 1 ô, Menglun, Yunnan Province, 19 May 1991, coll. Yinglun Wang \& Wanzhi Cai (NWAFU); 1 ô, Menglun, Yunnan Province, 20 May 1991, coll. Yinglun Wang \& Wanzhi Cai (NWAFU); 1 ô, Mengla, Yunnan Province, 9 Jun. 1991, coll. Yinglun Wang \& Wanzhi Cai (MNHN); 1 ${ }^{\lambda}$, Mengla, Yunnan Province, 10 Jun. 1991, coll. Yinglun Wang \& Wanzhi Cai (MNHN).

\section{Description}

Length, male (including tegmina) $(\mathrm{n}=5): 7.8-8.0 \mathrm{~mm}$.

Vertex 1.5 times longer in midline than broad at base, anterior margin V-shaped well marked, anterior and lateral margins elevated. Frons 1.5 times longer in midline than widest part, median carina weakly present. Pronotum 3.9 times broader at widest part than long in midline. Mesonotum 1.5 times broader at widest part than long in midline.

\section{Coloration}

Vertex greyish white with three slender and fuscous longitudinal stripes and two fuscous patches at base; anterior and lateral margins black (Fig. 19). Eyes brownish ochraceous (Fig. 19). Frons pale piceous in ventral view; sublateral carinae brown, with very narrow longitudinal stripes at inner side; lateral margins brown (Fig. 20). Clypeus pale piceous, with apical part dark brown (Fig. 20). Gena greyish white, with one fuscous transverse stripe crossing ocellus (Fig. 18). Ocelli red. Pronotum greyish white, with dark brown colour suffused in apical and median area on disc; median and lateral carinae ochraceous (Fig. 19). Mesonotum black, median and lateral carinae black (Fig. 19). Tegmina dark brown, costal margin with one greyish white marking along with two fuscous transverse stripes at basal 1/4; one rectangular greyish white marking at middle extending to median part of tegmina, with fuscous transverse stripes inside; two small greyish white irregular markings near apex of costal margin, and apical part greyish white, with fuscous sinuate stripe inside (Fig. 16). Hindwings pale brown. Legs pale piceous; fore and median femora and tibiae diffused with fuscous transverse stripes.

\section{Male terminalia}

Pygofer higher than wide in profile, with dorsal margin sloping posteriorly at basal $1 / 3$ and flattened at basal $2 / 3$, posterior margin slightly concave near middle, dorso-lateral angle acute (Fig. 21). Anal tube in dorsal view longer than wide, with apical part digitiform and lateral margin convex (Fig. 24); in lateral view, anal tube prolonged posteriorly beyond the anal opening point by a medio-dorsal extension gradually tapering to apex (Fig. 21). Gonostylus longer than high, dorsal margin sloping forward at basal 

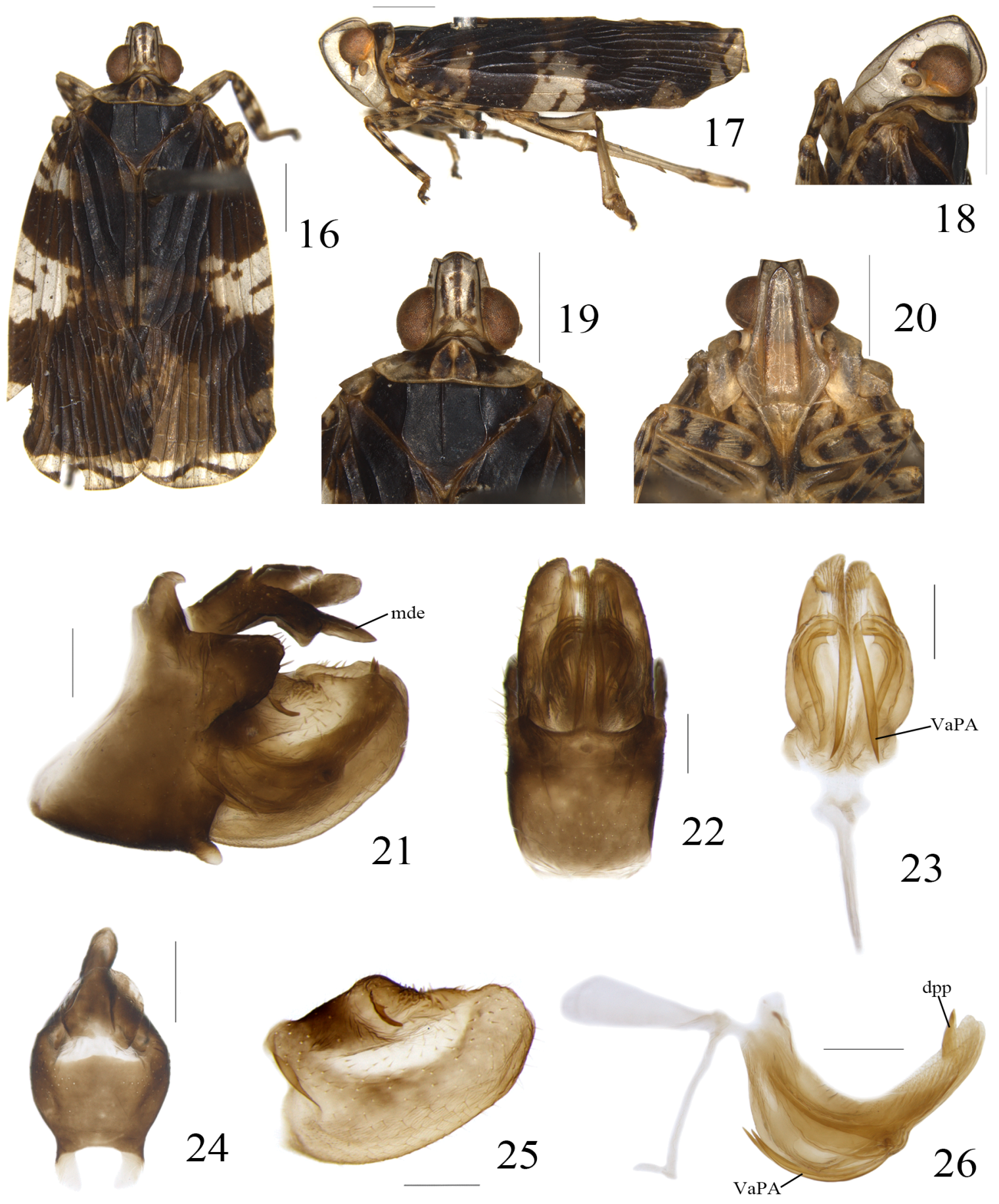

Figs 16-26. Pitambara impudica Wang \& Bourgoin, sp. nov., holotype, $\widehat{\partial}$. 16. Habitus, dorsal view. 17. Habitus, lateral view. 18. Head, lateral view. 19. Head and thorax, dorsal view. 20. Frons and clypeus. 21. Male terminalia, lateral view. 22. Male terminalia, ventral view. 23. Phallic complex, ventral view. 24. Anal tube, dorsal view. 25. Gonostylus, lateral view. 26. Phallic complex and tectiform structure, lateral view. Scale bars: $16-20=1 \mathrm{~mm} ; 21-26=0.2 \mathrm{~mm}$. 
part and sinuate at apical part, with a small hook-like process directed posteriorly near base; ventral margin obliquely rounded (Figs 21, 25). In lateral view, dorsal margin of periandrium regularly curved and deeply concave at middle, beyond the insertion level of aedeagus process, periandrium getting slender regularly and apex round, bearing a dorsal process oriented dorsally (Figs 26, 40), aedeagus bearing a pair of ventral-anterior processes very regularly curved and oriented anteriorly (Fig. 26). In ventral view, processes of aedeagus straight.

Pitambara tricorne Wang \& Wang, sp. nov. urn:1sid:zoobank.org:act:749B7FD4-6ABD-4E35-81C5-F3B926189F27

Figs $27-37,42-44$

\section{Diagnosis}

Within the Pitambara species presenting a rectangular costal hyaline patch on the tegmina (Fig. 1), P. tricorne sp. nov. is the only one presenting a whitish frons with two brown bands near lateral angles and sublateral brown carinae (Fig. 31). The "tricorne" shape of the periandrium's apex is unique.

\section{Etymology}

Named after a hat in fashion during the $18^{\text {th }}$ century in France, the "tricorne" was that of a triangular shape and folded in 3 horns. The apex of the periandrium has a similar shape. Name placed in apposition.

\section{Type material}

\section{Holotype}

CHINA: Õ, Menglun, Xishuangbanna, Yunnan Province, 596 m, 2 Dec. 2009, coll. Guo Tang \& Zhiyuan Yao (IZCAS).

\section{Paratypes}

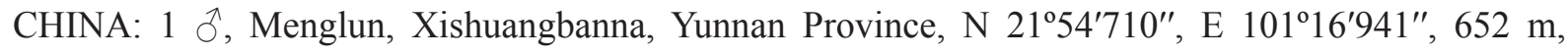
16 Nov. 2009, coll. Guo Tang \& Zhiyuan Yao (IZCAS).

\section{Description}

Length, male (including tegmina) $(\mathrm{n}=2): 7.8-8.1 \mathrm{~mm}$.

Vertex 1.3 times longer in midline than broad at base, lateral margins elevated. Frons 1.4 times longer in midline than widest part. Pronotum 4.1 times broader at widest part than long in midline. Mesonotum 1.5 times broader at widest part than long in midline.

\section{Coloration}

Vertex greyish white, with three slender fuscous longitudinal stripes; lateral stripes with small fuscous patches at base; lateral margins black (Fig. 30). Eyes grey (Fig. 30). Frons white; two very small fuscous spots near apex and two fuscous bands near lateral angles; sublateral carinae brown (Fig. 31). Clypeus dark brown, median area yellow (Fig. 31). Gena greyish white, with one fuscous transverse stripe crossing ocellus (Fig. 29). Ocelli grey. Pronotum with median area between eyes black and lateral area grey (Fig. 30). Mesonotum black (Fig. 30). Tegmina dark brown, costal margin with several fuscous transverse stripes at basal $1 / 3$; one sub-rectangular white marking at middle extending to median part of tegmina with two fuscous transverse stripes inside; two small irregular white markings along apical part of costal margin, and apex of tegmina white, one fuscous sinuate stripe inside (Fig. 27). Hindwings pale brown. Legs pale tawny; fore and middle femora and tibiae diffused with several thick fuscous transverse stripes, hind femora dark brown and tibia yellow; lateral and apical spines black. 

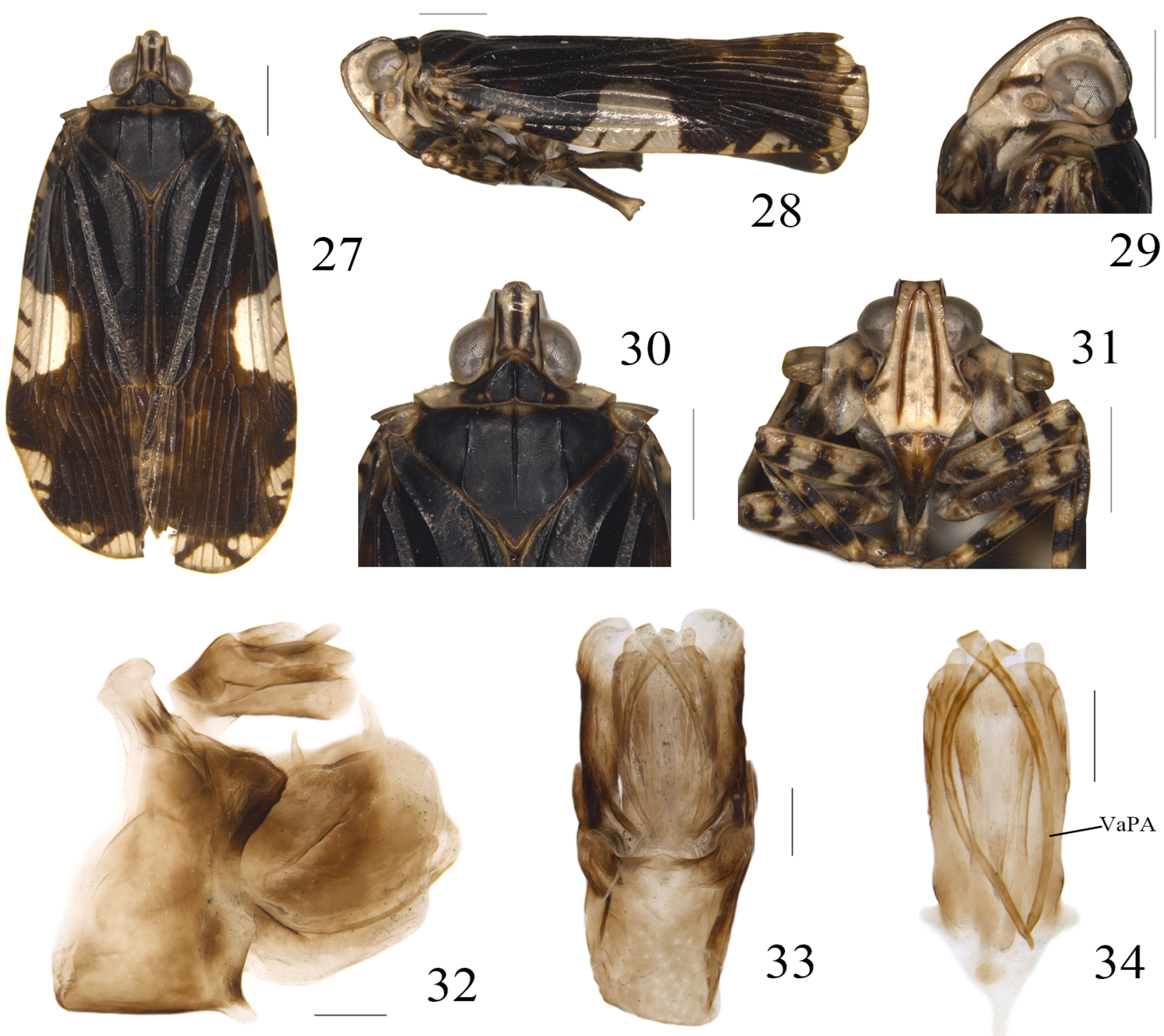

29
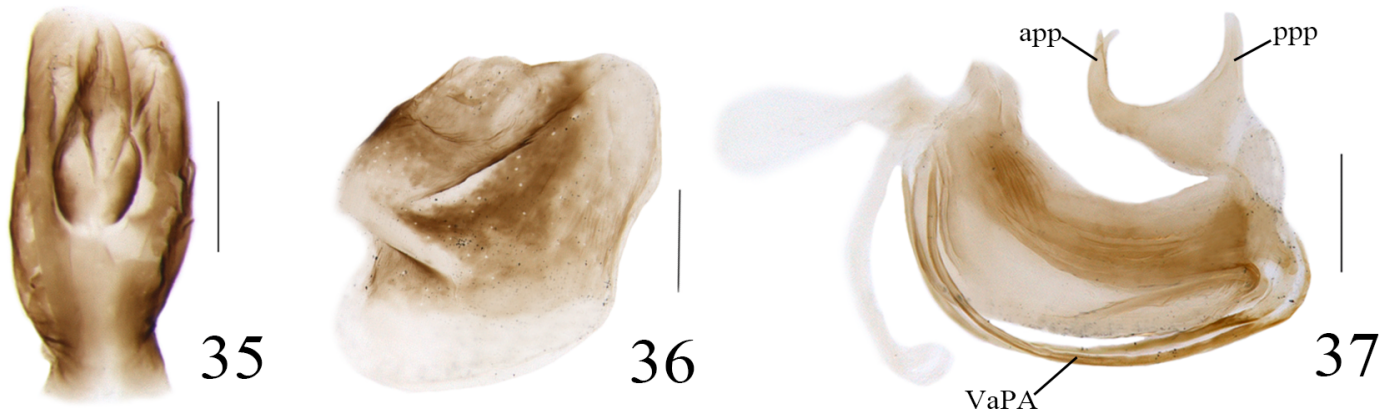

Figs 27-37. Pitambara tricorne Wang \& Wang, sp. nov., holotype, ठ. 27. Habitus, dorsal view. 28. Habitus, lateral view. 29. Head, lateral view. 30. Head and thorax, dorsal view. 31. Frons and clypeus. 32. Male terminalia, lateral view. 33. Male terminalia, ventral view. 34. Phallic complex, ventral view. 35. Anal tube, dorsal view. 36. Gonostylus, lateral view. 37. Phallic complex and tectiform structure, lateral view. Scale bars: $27-31=1 \mathrm{~mm} ; 32-37=0.2 \mathrm{~mm}$. 


\section{Male terminalia}

Pygofer higher than wide in profile, with dorsal margin sloping posteriorly, posterior margin slightly concave near middle, postero-dorsal angle acute (Fig. 32), posterior margin cut out from the top down to the $2 / 3$. Anal tube in dorsal view longer than wide, cylindrical, with lateral margin nearly parallel; anal opening situated at mid length (Fig. 35); in lateral view with a pair of small ventral teeth hidden near apex

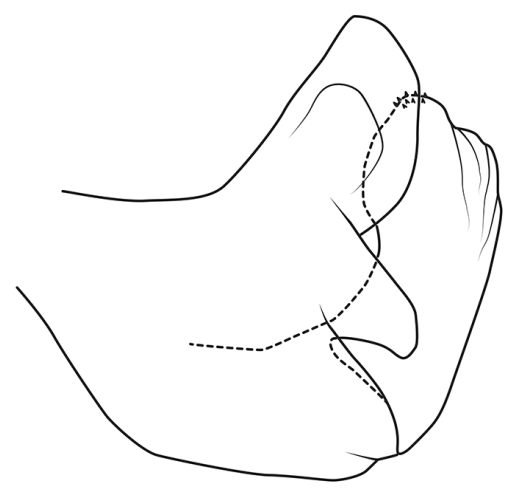

38

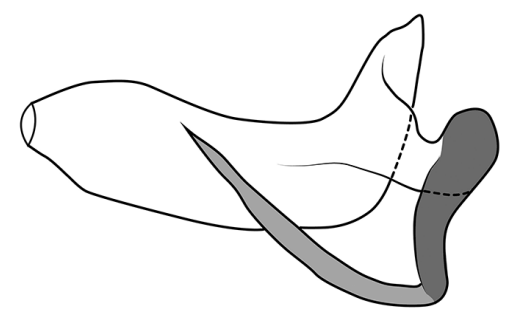

39

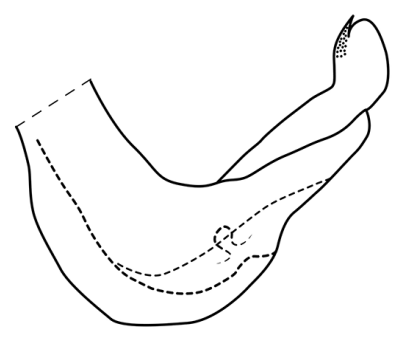

40

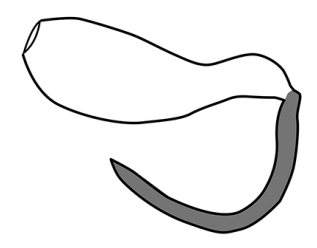

41
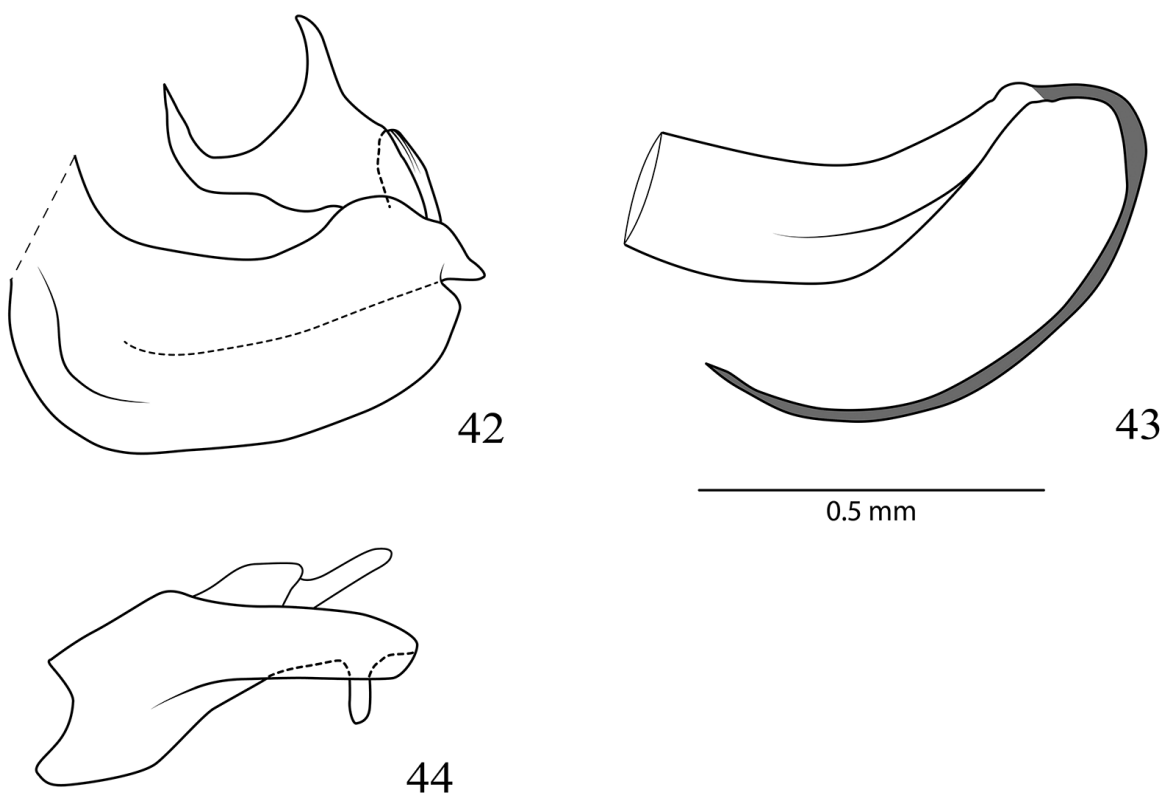

Figs 38-44. Phallic complexes and anal tube. 38-39. Pitambara triremiprocta Wang \& Soulier-Perkins, sp. nov. 38. Periandrium, lateral view. 39. Aedeagus, lateral view. 40-41. Pitambara impudica Wang \& Bourgoin, sp. nov. 40. Periandrium, lateral view. 41. Aedeagus, lateral view. 42-44. Pitambara tricorne Wang \& Wang, sp. nov. 42. Periandrium, lateral view. 43. Aedeagus, lateral view. 44. Anal tube, lateral view. 
(Fig. 44). Gonostylus higher than broad; dorsal margin sinuate, with a small hook-like process directed posteriorly near base, ventral margin curved (Figs 32, 36). In lateral view, dorsal margin of periandrium gently and regularly curved; apex of periandrium extremely developed and ending posteriorly into two processes and anteriorly by a process apically bifid, all processes oriented dorsally (Figs 37, 42); margin between anterior and posterior processes largely rounded. Aedeagus bearing a pair of ventro-posterior processes very long and slender, regularly curved and oriented antero-dorsally (Figs 37, 43).
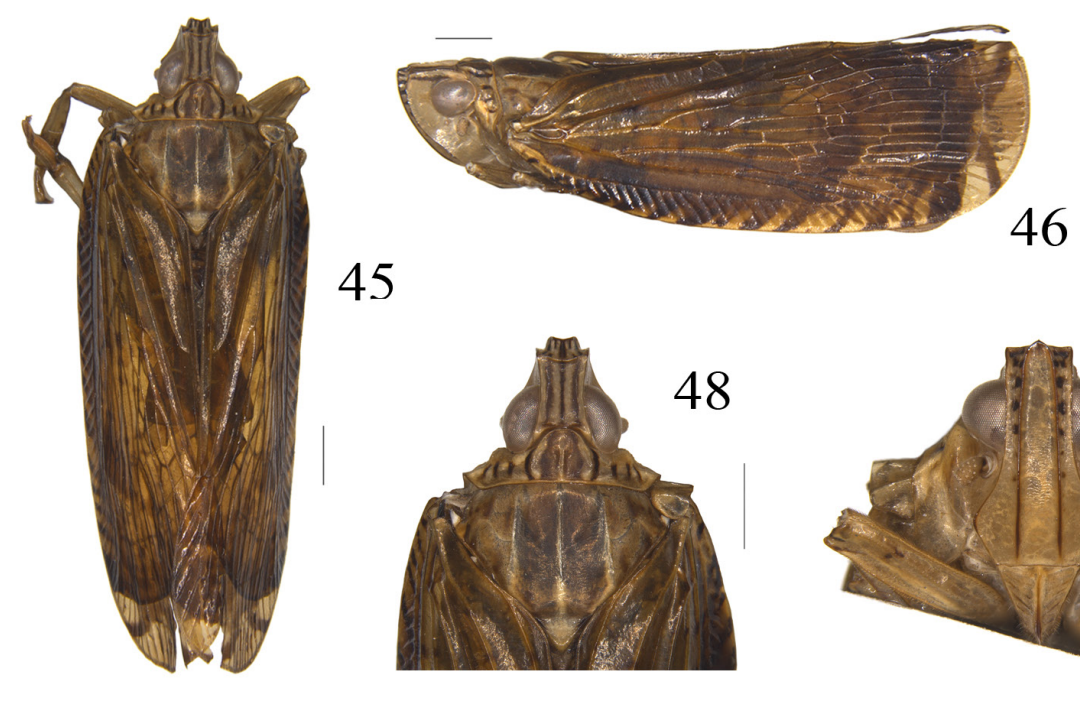

45
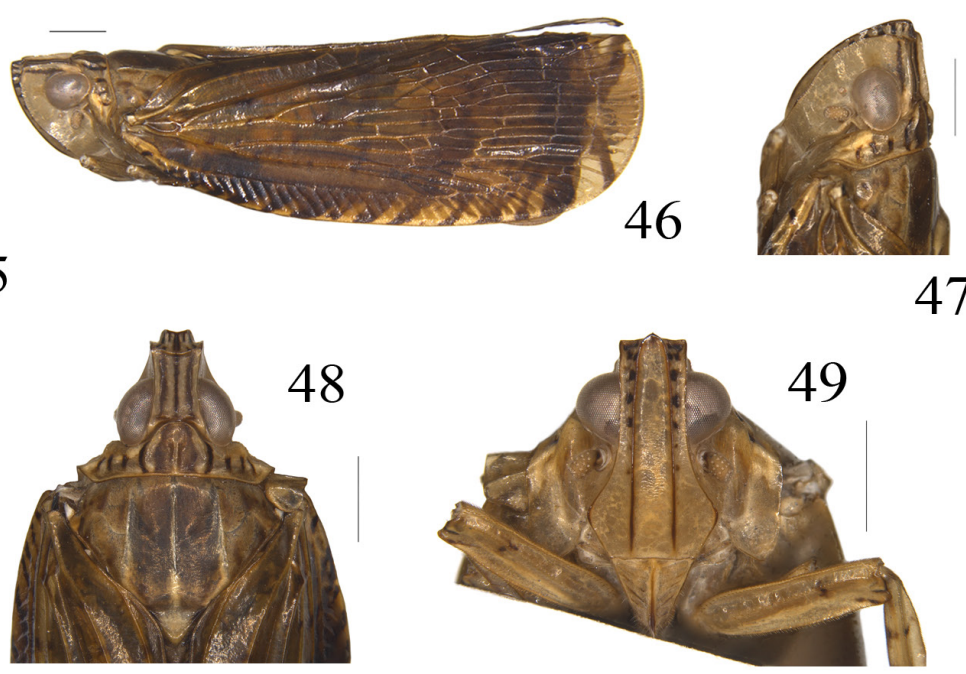

47
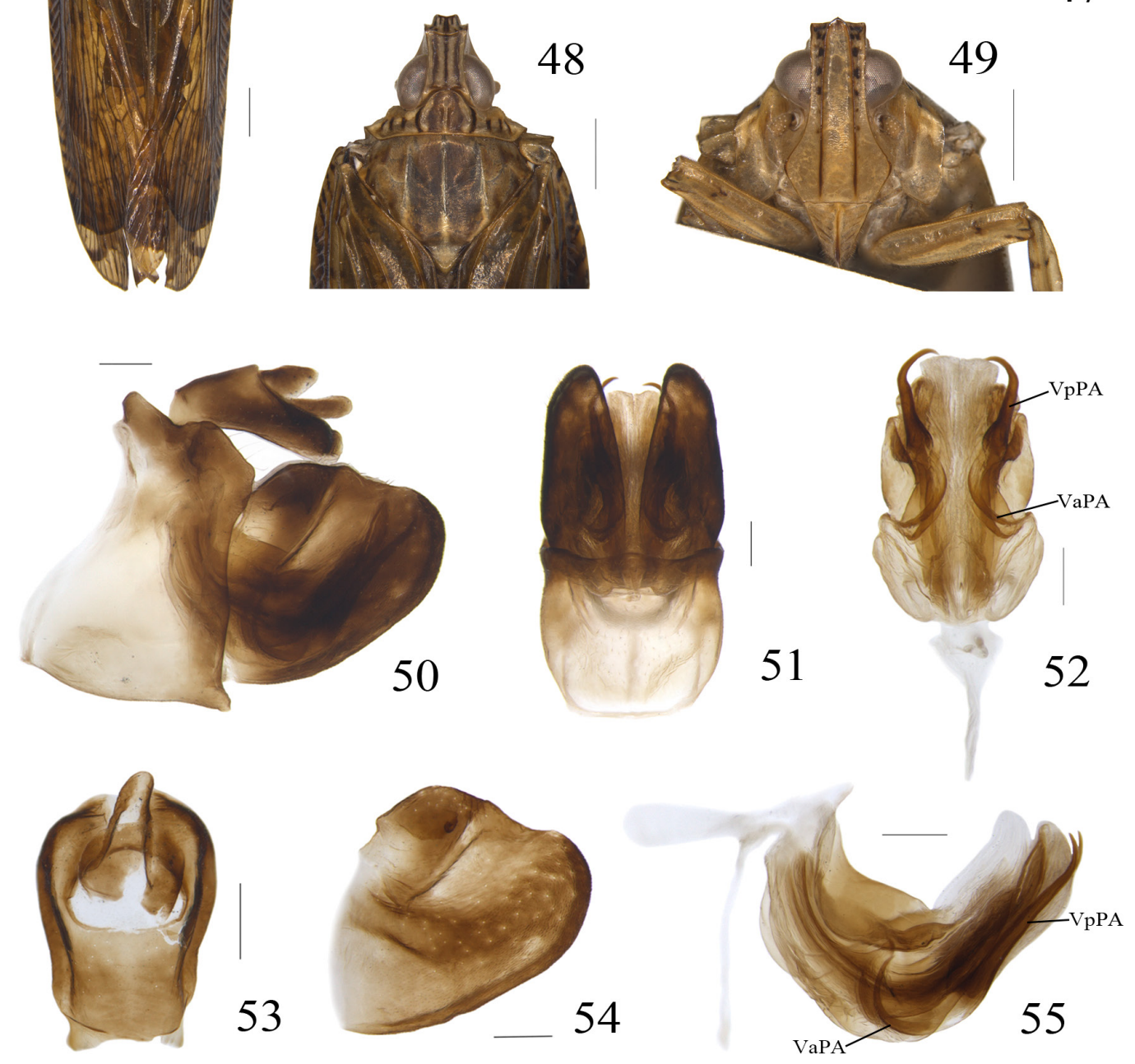

Figs 45-55. Serida parenthesisflexuosa Wang \& Soulier-Perkins, sp. nov., holotype, ô. 45. Habitus, dorsal view. 46. Habitus, lateral view. 47. Head, lateral view. 48. Head and thorax, dorsal view. 49. Frons and clypeus. 50. Male terminalia, lateral view. 51. Male terminalia, ventral view. 52. Phallic complex, ventral view. 53. Anal tube, dorsal view. 54. Gonostylus, lateral view. 55. Phallic complex and tectiform structure, lateral view. Scale bars: $45-49=1 \mathrm{~mm} ; 50-55=0.2 \mathrm{~mm}$. 
Genus Serida Walker, 1857

Serida Walker, 1857: 158.

Serida - Distant 1906: 324. — Melichar 1915: 343.

\section{Type species}

Serida latens Walker, 1857. Subsequent designation by Distant (1906: 324).

Serida parenthesisflexuosa Wang \& Soulier-Perkins, sp. nov. urn:1sid:zoobank.org:act:3B6F9F67-8C94-48F5-B71C-28EC3F7F8505

Figs $45-57$

\section{Diagnosis}

This species can be easily indentified by vertex showing three brown parallel longitudinal bands (Fig. 48); aedeagus bearing two pairs of ventral processes, ventral anterior processes strongly curved and antero-dorsally oriented, ventral posterior processes long and nearly straight with apex oriented dorsally (Figs 55, 57).

\section{Etymology}

The dorsal margin of the periandrium being shaped like a curly bracket, the name is made from a concatenation of two Latin words: parenthesis meaning "bracket" and flexuosa meaning "sinuous".

\section{Type material}

\section{Holotype}

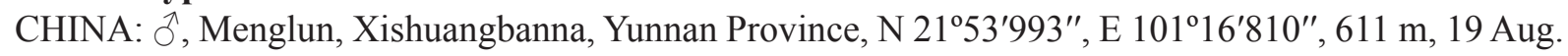
2007, coll. Guo Zheng (IZCAS).

\section{Paratypes}

CHINA: $2 \hat{\jmath}$, same data as holotype (IZCAS).

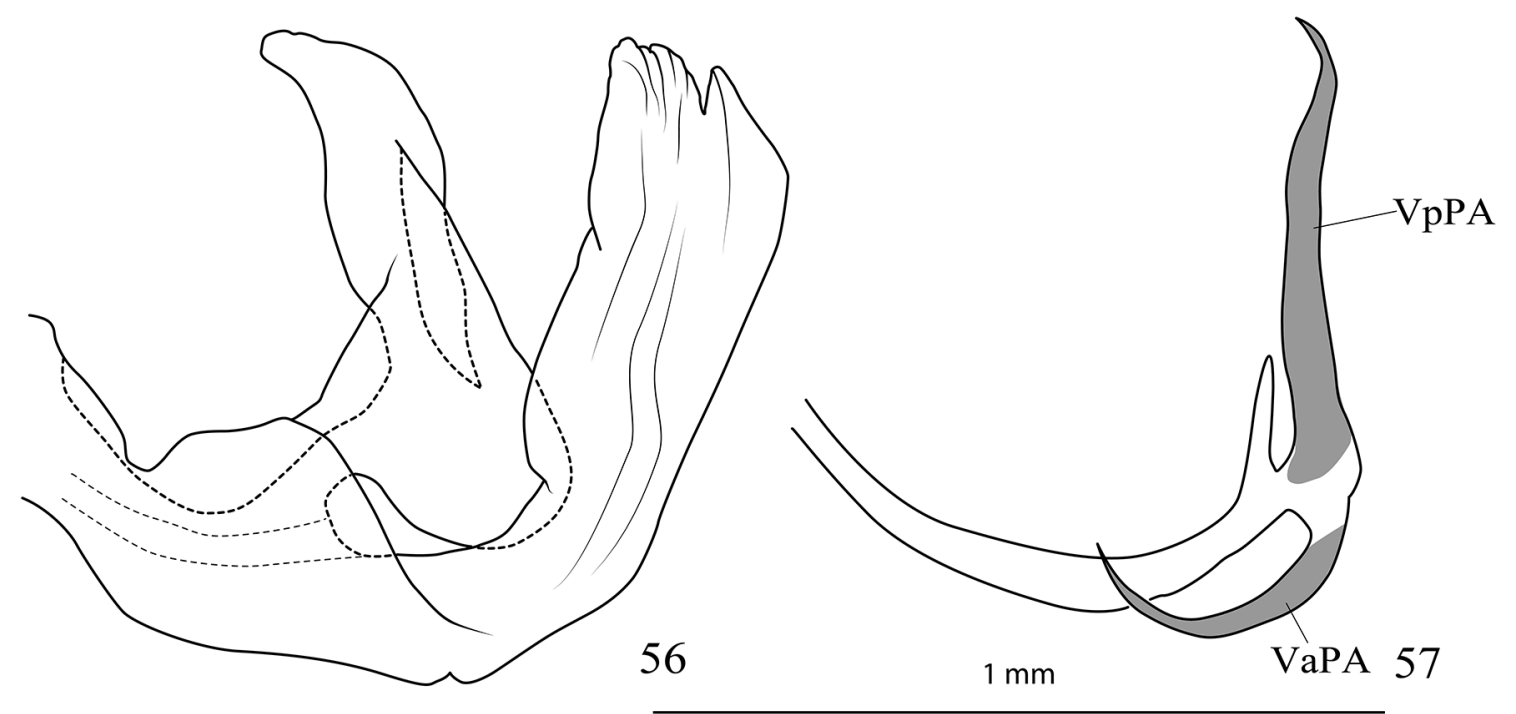

Figs 56-57. Serida parenthesisflexuosa Wang \& Soulier-Perkins, sp. nov. 56. Periandrium, lateral view. 57. Aedeagus, lateral view. 


\section{Description}

Length, male (including tegmina) $(\mathrm{n}=3): 10.5-11.0 \mathrm{~mm}$.

Vertex in dorsal view 1.1 times longer in midline than wide at base; apical margin slightly concave; lateral margins slightly excavate. Frons 1.7 times longer in midline than widest part, 2.9 times longer in midline than wide at base; sublateral carinae parallel and elevated, fused dorso-apically and forming an acute angle. Pronotum 3.7 times broader at widest part than long in midline. Mesonotum 1.0 times broader at base than long in midline. Tegmina 2.8 times longer at longest part than broad.

\section{Coloration}

Vertex ochraceous, with three brown paralleled longitudinal bands (Fig. 48). Eyes grey (Fig. 48). Frons protrusion in front of vertex in dorsal view ochraceous, with one brown transverse band at middle and several dark brown patches on each side (Fig. 48). Frons ochraceous; sublateral carinae brown, with 7 brown patches on each side along outer rim of sublateral carinae; lateral margins brown (Fig. 49). Ocelli tawny. Genae ochraceous. Pronotum ochraceous, with curved brown band along lateral carinae and three brown longitudinal stripes in lateral area on each side; carinae ochraceous (Fig. 48). Mesonotum tawny, median and lateral carinae pale yellow (Fig. 48). Tegmina dark tawny; costal margin with several brown oblique transverse stripes; apical part with one sinuate brown stripe at tip (Figs 45-46). Legs ochraceous.

\section{Male terminalia}

Pygofer higher than wide in profile, with dorsal margin sloping down posteriorly on the $1 / 3$ of anterior part; postero-dorsal angle truncated; posterior margin slightly concave medially (Fig. 50). Anal tube in dorsal view longer than wide, cylindrical, with apical margin rounded (Fig. 53). In lateral view, gonostylus approximately as broad as high; dorsal margin slightly sinuate, on the upper anterior side a very small lateral process curving down, ventro-posterior margin oblique (Figs 50, 54). In lateral view, dorsal margin of periandrium "curly brackets" shaped (Figs 55-56). Aedeagus bearing two pairs of ventral processes, ventral anterior processes hidden in the periandrium folds, strongly curved and antero-dorsally oriented, ventral posterior processes nearly straight with apex oriented dorsally (Figs 55, 57).

Genus Lacusa Stål, 1862

Lacusa Stål, 1862: 309.

Lacusa - Distant 1906: 323. — Melichar 1915: 354.

\section{Type species}

Elasmoscelis fuscofasciata Stål, 1854. Designated by Stål (1862: 309).

Key to species of the genus Lacusa Stål, 1862 (modified from Xing \& Chen 2014)

1. Tip of the tegmina bearing a branched pattern (Fig. 63) .....

- Tip of the tegmina bearing an unbranched pattern (Fig. 74) L. fuscofasciata (Stål, 1854)

2. Median periandrium processes long, extending beyond the apex of periandrium dorsally ......

- Median periandrium processes short, not extending dorsally beyond the apex of periandrium (Fig. 70, Mpp) .

3. Median extension of periandrium as developed as paired median processes of the periandrium........

L. digitata Xing \& Chen, 2014

- Median extension of periandrium longer and wider than paired median processes of the periandrium (Fig. 70) L. yunnanensis Chou \& Huang, 1985 stat. rev. 
Lacusa yunnanensis Chou \& Huang, 1985 stat. rev.

Lacusa yunnanensis Chou \& Huang in Chou et al., 1985: 128.

Lacusa fuscofasciata - Liang 1996: 146. [syn. error]

\section{Note}

In 1854, Stål described a new species Elasmoscelis fuscofasciata from "India orientalis" (Stål 1854). In 1862, he transferred it to Lacusa Stål, 1862 and just mentioned that the specimen was a male, without providing any description concerning the terminalia. Distant (1906) and Melichar (1915) identified some specimens as being L. fuscofasciata and illustrated their descriptions with drawing of the habitus and a frontal view of the head. In 1985, Chou and Huang (in Chou et al. 1985) described a new species, Lacusa yunnanensis Chou \& Huang, 1985. The authors mentioned that L. yunnanensis closely resembles L. fuscofasciata and differs only by two characters: a branched fuscous transverse band near the outer margin on the tegmina and a meso- and metathorax fuscous versus an unbranched band on the tegmina and a meso- and metathorax slightly brown for L. fuscofasciata. Chou and Huang indicated that the holotype was a female and provided a drawing of the habitus and a frontal view of the head.

In 1996, Liang placed L. yunnanensis as a synonym of L. fuscofasciata. He wrote that after having examined material from different provinces in China and the female holotype of L. yunnanensis, the latter represents part of the colour variability within L. fuscofasciata. In the PhD thesis of SoulierPerkins (unpublished 1997), some illustrations for the genus Lacusa were provided. As such, drawings of male terminalia were provided for the first time for what she believed to be $L$. fuscofasciata according to the available description in the literature at this time - the corresponding habitus is here provided in Fig. 86. In 2000, Liang provided an illustration of male terminalia of L. fuscofasciata, in accordance with Soulier-Perkins (unpublished 1997). In 2014, Xing and Chen described two new species, Lacusa producta Xing \& Chen, 2014 and Lacusa digitata Xing \& Chen, 2014. The descriptions were followed by some illustrations: pictures of the specimens and drawings of the male terminalia. They allow an easy recognition of the species when males are available. The authors also provided pictures and drawings of a specimen they believed to be L. fuscofasciata, and the male terminalia in their paper are in accordance with the drawings of Soulier-Perkins (unpublished 1997) and Liang (2000).

We checked the holotype of L. yunnanensis. Our surprise was big when 1) we noticed it was not a female but a male and 2) the drawing provided by Chou et al. (1985) was not the one of the holotype, which could explain the discrepancy between the description of the shape of the band at the tip of the tegmina and its illustration. We provide here the pictures of the holotype and the drawings of the male terminalia that we prepared (Figs 58-70). In Fig. 63, we can clearly see what the authors described as a branched band near the outer margin of the forewing. This character and the male terminalia are clearly different from what is usually recognised as being $L$. fuscofasciata, which would lead us to invalidate Liang's synonymy.

Since all the illustrations provided in the literature for L. fuscofasciata were done from specimens identified as such but not from the holotype, we also borrowed and examined the holotype in order to prepare the male terminalia and illustrate them. A second surprise was waiting for us as the holotype of L. fuscofasciata is not a male but a female (Figs 74-78). However, the pattern at the tip of the tegmina is unbranched and distinct from the branched band observed in L. yunnanensis.

Lacusa species identification is therefore reanalysed here after realising all these facts and data. In the material examined, all the males with an unbranched pattern on the tegmina (Figs 85-86) always showed the same male terminalia as in Soulier-Perkins (unpublished 1997) (genitalia of male with habitus as in Fig. 86), Liang (2000) and Xing \& Chen (2014). We also examined 4 females (including the holotype 

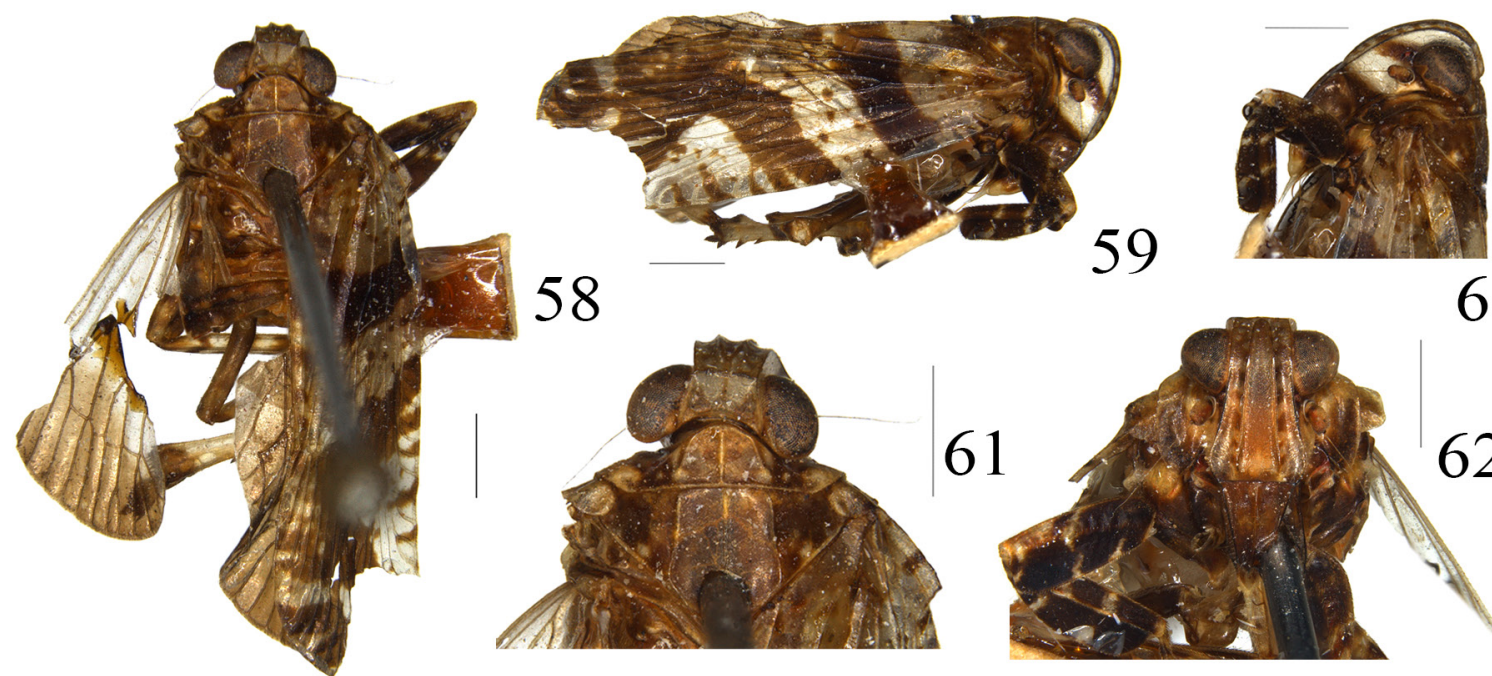

\section{8}
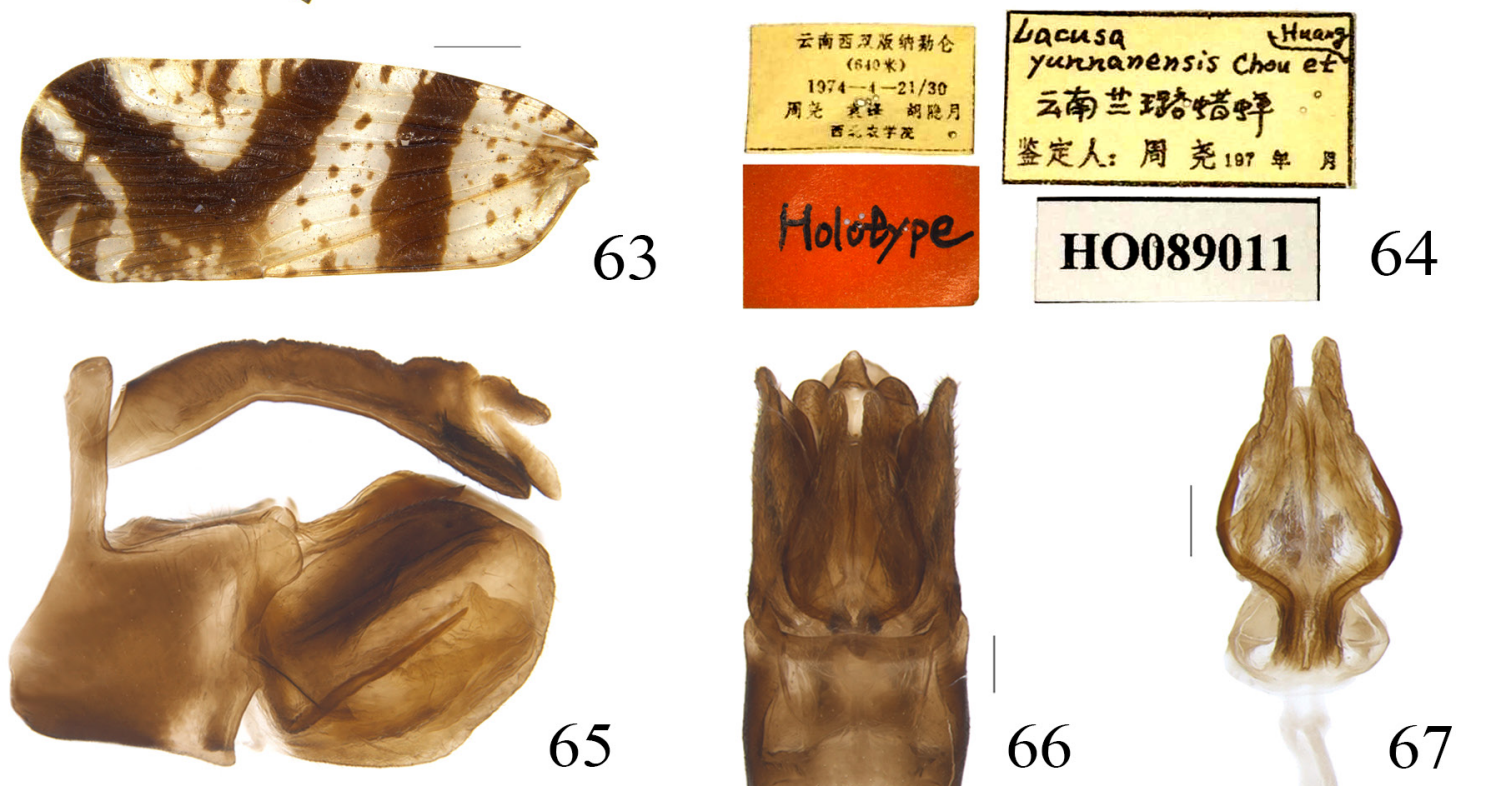

65
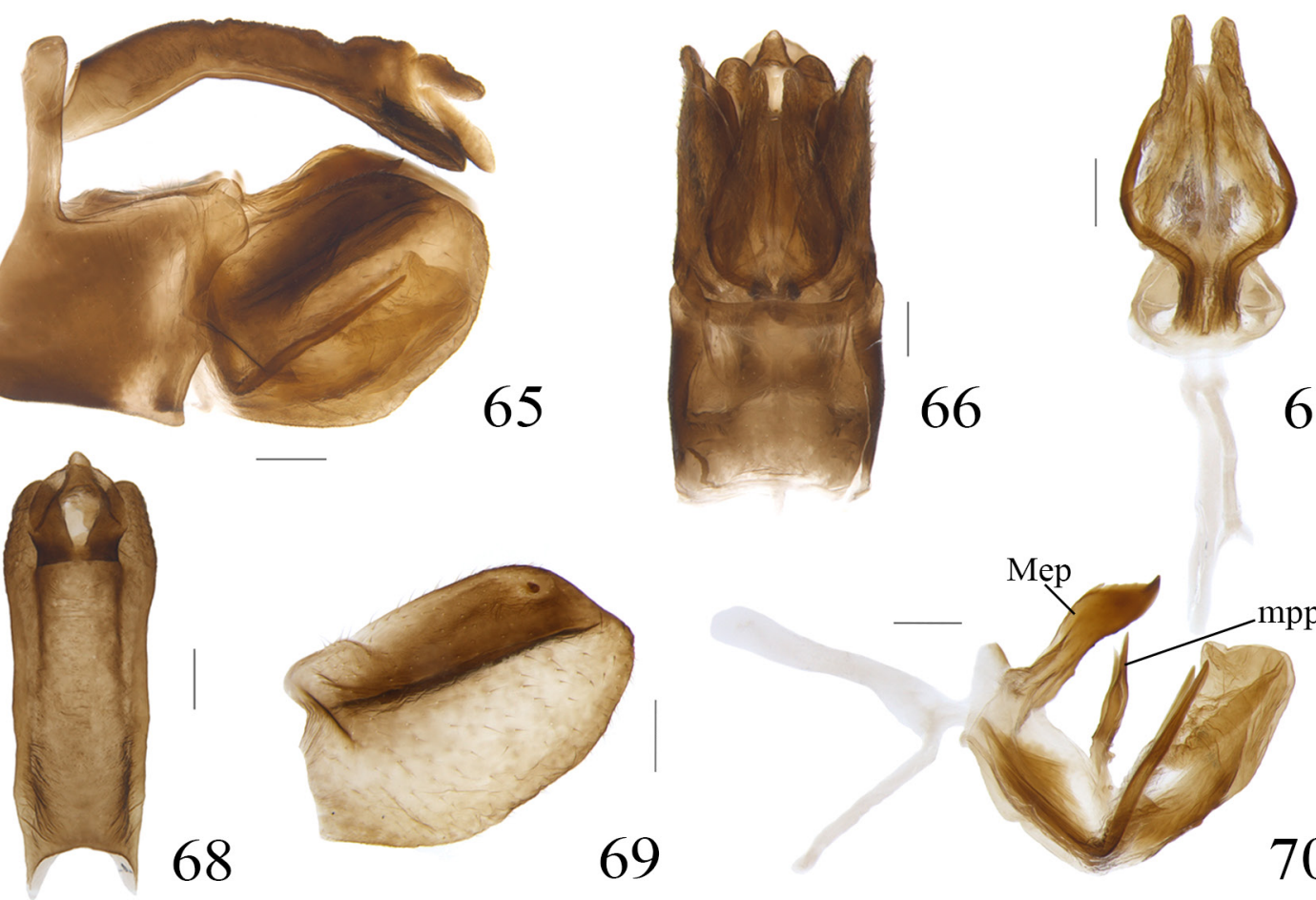

66

67

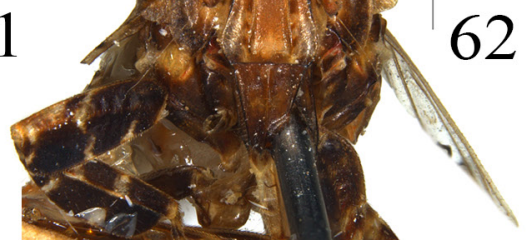

H0089011 64

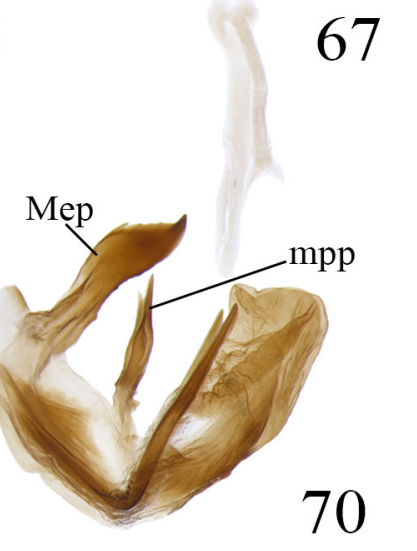

Figs 58-70. Lacusa yunnanensis Chou \& Huang, 1985 stat. rev., holotype, $\widehat{\jmath}$. 58. Habitus, dorsal view. 59. Habitus, lateral view. 60. Head, lateral view. 61. Head and thorax, dorsal view. 62. Frontal view. 63. Tegmina. 64. Labels. 65. Male terminalia, lateral view. 66. Male terminalia, ventral view. 67. Phallic complex, ventral view. 68. Anal tube, dorsal view. 69. Gonostylus, lateral view. 70. Phallic complex and tectiform structure, lateral view. Scale bars: $58-63=1 \mathrm{~mm} ; 65-70=0.2 \mathrm{~mm}$. 
of L. fuscofasciata), presenting an unbranched pattern at the tip of the tegmina. The abdomen in all four specimens presents ventrally a segment VII of a "simple shape". The posterior margin is slightly produced posteriorly in its median part. Depending on the specimen, this margin is more or less rounded (Figs 83, 87-88). We now conclude that all the specimens presenting the unbranched pattern on the tegmina belong to the same species: L. fuscofasciata.

From the pictures provided by Xing and Chen for L. producta and L. digitata (Xing \& Chen 2014), we noticed that the pattern at the tip of their tegmina is comparable to the branched pattern of L. yunnanensis
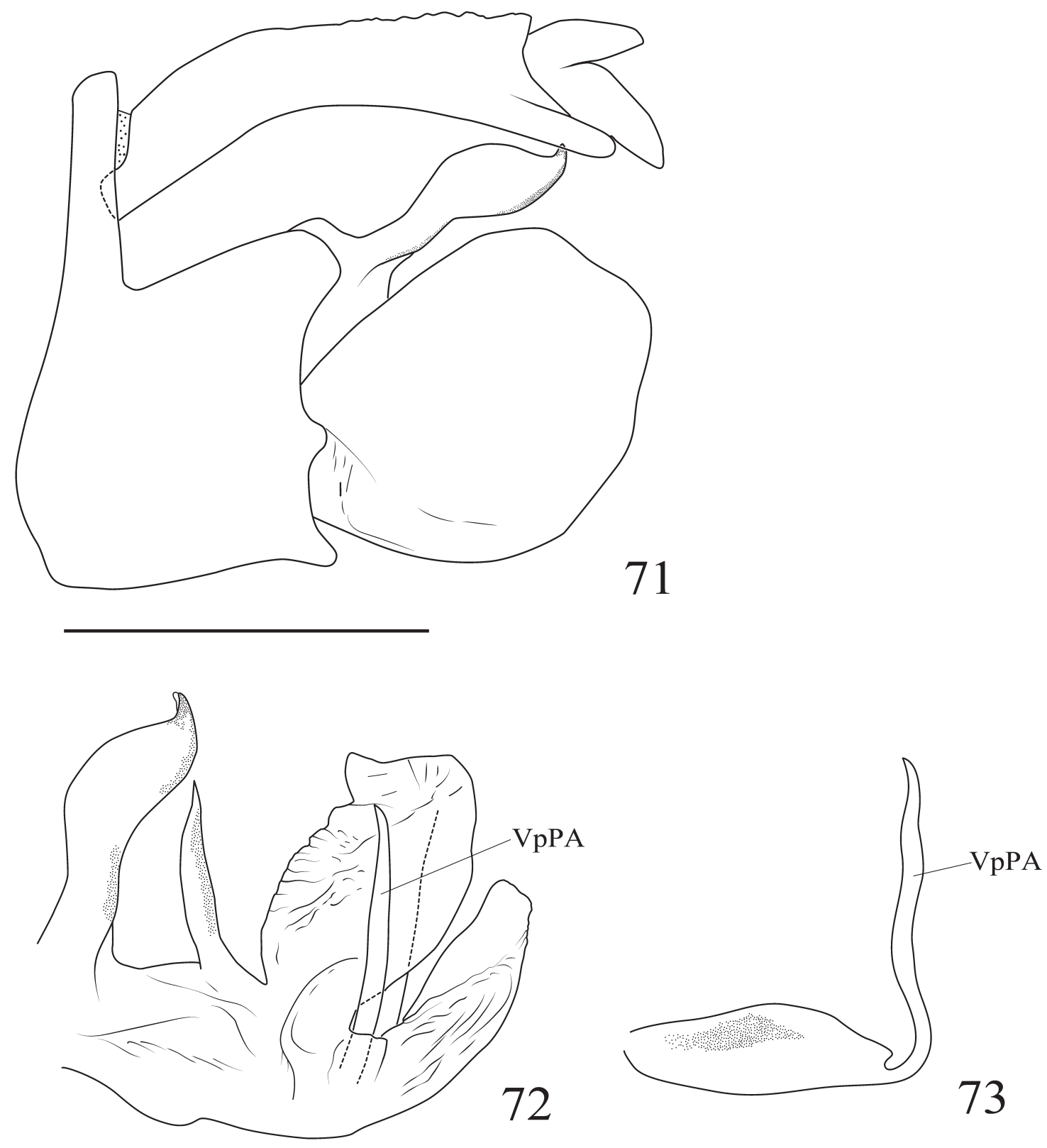

Figs 71-73. Lacusa yunnanensis Chou \& Huang, 1985 stat. rev., from Thailand, Chiangmai Province. 71. Male terminalia, lateral view. 72. Phallic complex: periandrium and aedeagus, lateral view. 73. Aedeagus, lateral view. Scale bars $=1 \mathrm{~mm}$. 
but the three species can be clearly identified from each other by their male terminalia. In the material examined, six females presented a segment VII highly modified as in Figs 80, 89 and 90. Moreover, five of them presented a branched pattern at the tip of the tegmina, the sixth female had both tegmina damaged with the tips missing. However, this female was collected in the same place and date as a male identified as L. yunnanensis because of its terminalia. The VII segment illustrated in Fig. 89 belongs to this female and could be considered as illustrating what a female of the species L. yunnanensis looks like. This highly modified segment VII is associated with a branched pattern on the tegmina and as such not identified as L. fuscofasciata.

For all these reasons, L. yunnanensis is reinstated as a valid species and the already known illustrations of the terminalia of $L$. fuscofasciatia should be considered as valid.

From the examined material we noticed that L. fuscofasciata and L. yunnanensis are not found in the same areas. L. yunnanensis seems to be located in the South-West part of the Yunnan Province with its distribution extending to the north of Thailand. L. fuscofasciata appears to be more broadly distributed from South to North Vietnam and into the Chinese provinces of Guangxi and Guizhou. The holotype of $L$. fuscofasciata was collected in "India Orientalis" which is very vague since, at that time, this area corresponded to what actually is known as India, Bangladesh, a part of China and all of Southeast Asia.

\section{Material examined}

\section{Elasmoscelis fuscofasciata}

Holotype + , Ind[ia] or[ientalis], NHRS-GULI 000027588 (SMNH).

VIETNAM: L. fuscofasciata: 1 §, museum Paris, Tonkin, env. immédiats de Lao-Kay, CAPne SAUVEZ,

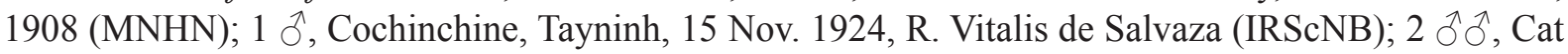
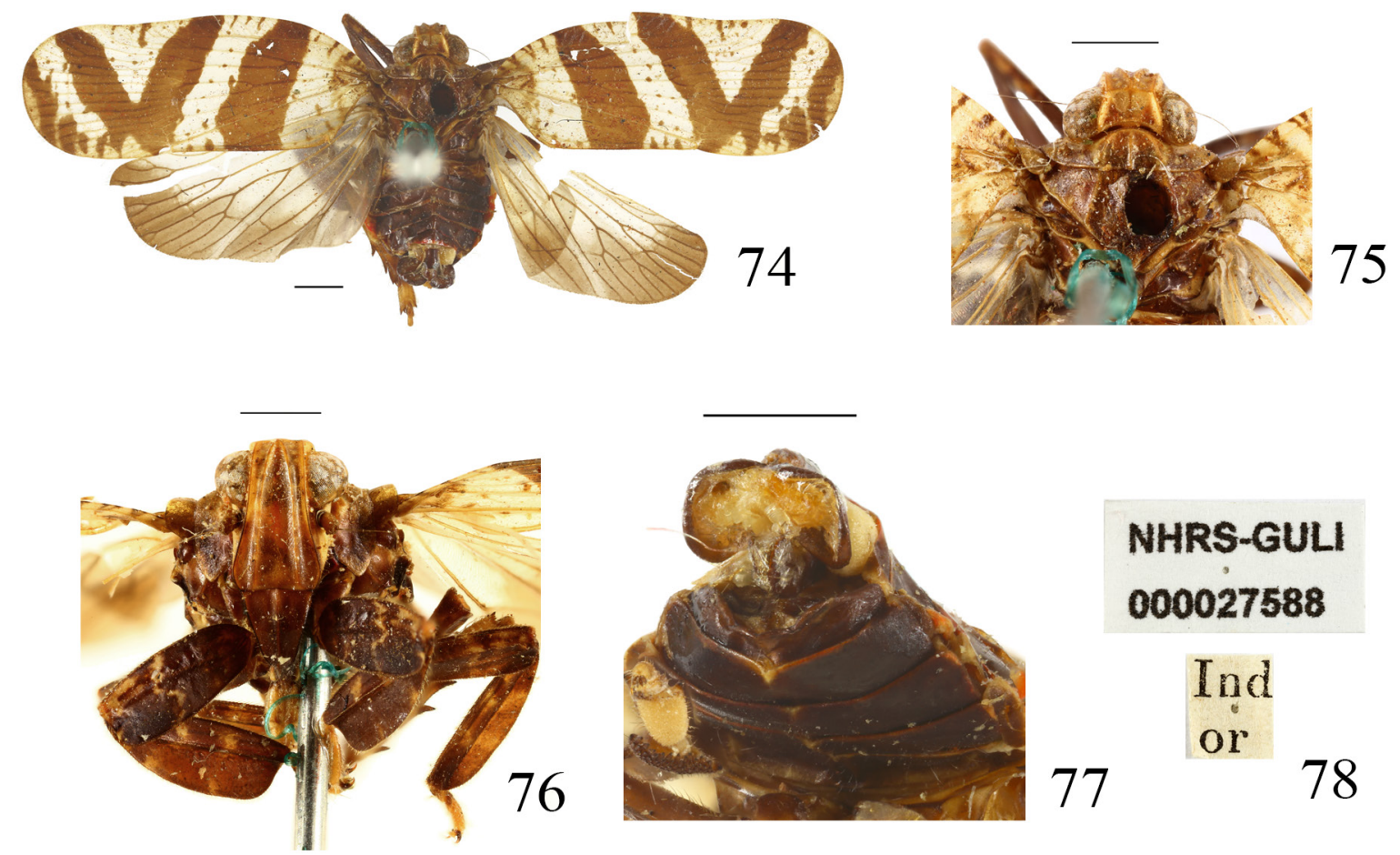

Figs 74-78. Lacusa fuscofasciata (Stål, 1854), holotype, ․ 74. Habitus, dorsal view. 75. Head and thorax, dorsal view. 76. Frons and clypeus, frontal view. 77. Female terminalia, 3/4 ventral view. 78. Labels. Scale bars $=1 \mathrm{~mm}$. 

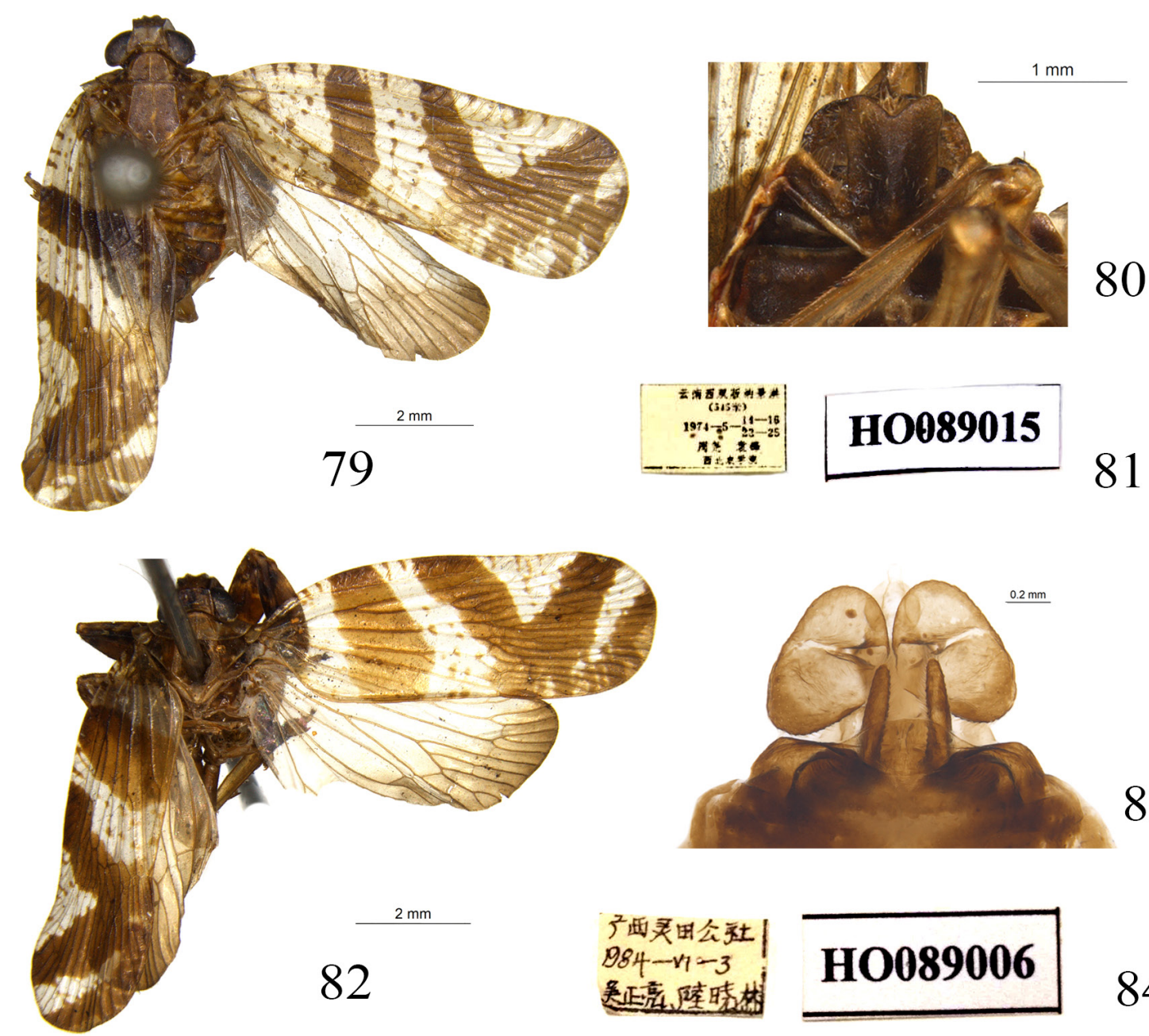

83
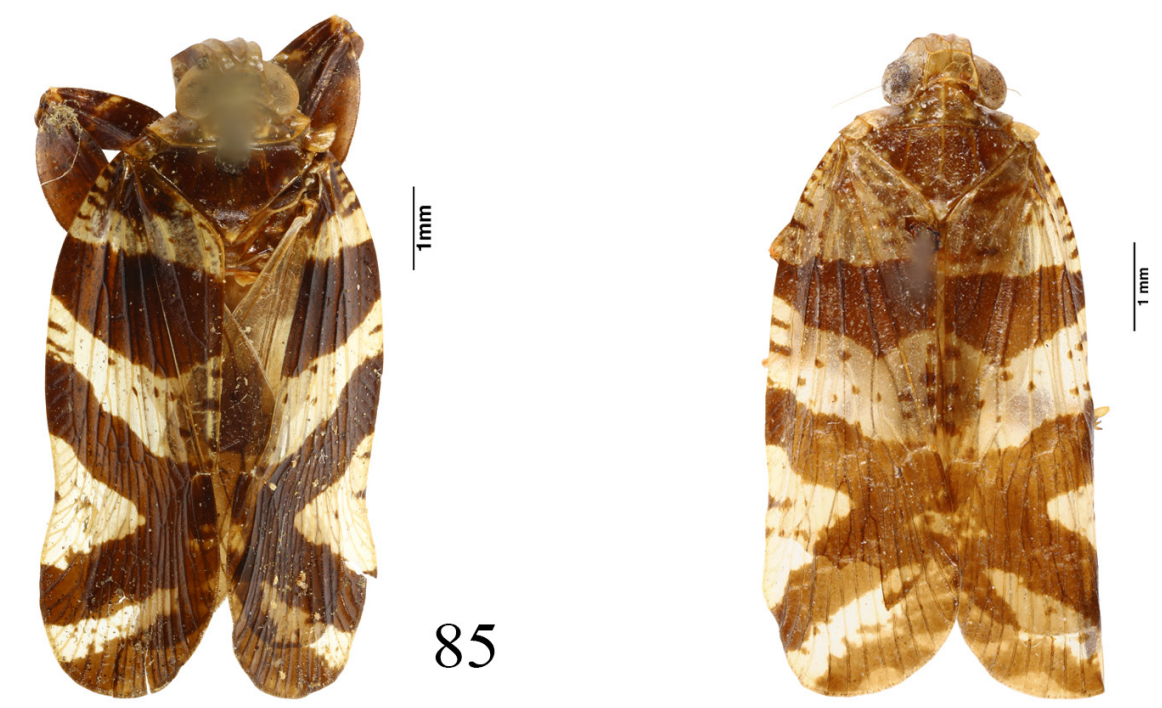

86

Figs 79-86. Lacusa Stål, 1862 specimens. 79-81. from China, Yunnan Province. 79. Habitus, dorsal view.

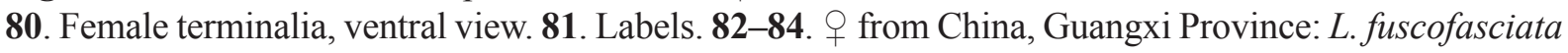
(Stål, 1854). 82. Habitus, dorsal view. 83. Female terminalia, ventral view. 84. Labels. 85. $\overbrace{}^{\top}$ from Tonkin, Lao-Kay; habitus, dorsal view. 86. $\widehat{\overbrace{}}$ from Vietnam, Mt Lang Bian; habitus, dorsal view. 
Tien N.P., $11^{\circ} 26^{\prime} \mathrm{N} 107^{\circ} 26^{\prime} \mathrm{E}, 6-16$ Jul. 2012, Leg. J. Constant \& J. Bresseel, I.G. 32.161 (IRScNB);

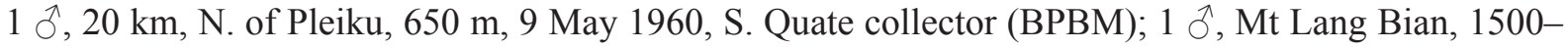
2000 m, 19 May-8 Jun.1961, N.R. Spencer collector Bishop (BPBM); 1 đ̂, Lò Gò-Xa Mát, 7 Nov. 2003 (VNMN).

CHINA: 2 우, China, Guangxi Province, Lingtian gongshe, 3 Jun. 1984 (NWAFU); 1 , Guizhou Province, Luodian, 15 Jul. 1982 (NWAFU).

\section{L. yunnanensis}

CHINA: holotype, Ô, Menglun, Xishuangbanna, Yunnan Province, 640 m, 21-30 Apr. 1974, coll. Io Chou, Feng Yuan \& Yinyue Hu (NWAFU); 1 đૈ, Xishuangbanna, Yunnan Province, 17 Apr. 1982, coll. Sumei Wang \& Jingruo Zhou (NWAFU).

THAILAND: 1 §, Loei, Na Haeo, 9 Feb. 1999, gallery forest, river, Leg. P. Grootaert (IRScNB); 1 ð, 1 , Chiangmai prov.: Fang (Agr. Exp. Station), 600 m, 14 Jun. 1965, P.D. Ashlock collector, Bishop Mus., U.S.-Japan Sci. coop. program (BPBM); 1 §̃, Chiangdao, 3-11 Apr. 1958, T. C. Maa (BPBM).

\section{Unidenfied materials}

THAILAND: 1 + , Na Haeo, 15-22 Aug. 2003, Leg. P. Grootaert (IRScNB).

CHINA: 1 + , Jinghong, Xishuangbanna, Yunnan Province, 545 m, 14-16 May 1974, coll. Io Chou \& Feng Yuan (NWAFU); 2 q, , Menglun, Xishuangbanna, Yunnan Province, 24 Apr. 1982, coll. Sumei Wang \& Jiangruo Zhou (NWAFU); 1 \&, Xiaomengyang, Yunnan Province, 23 Apr. 1982, coll. Jiangruo Chou \& Sumei Wang (NWAFU).
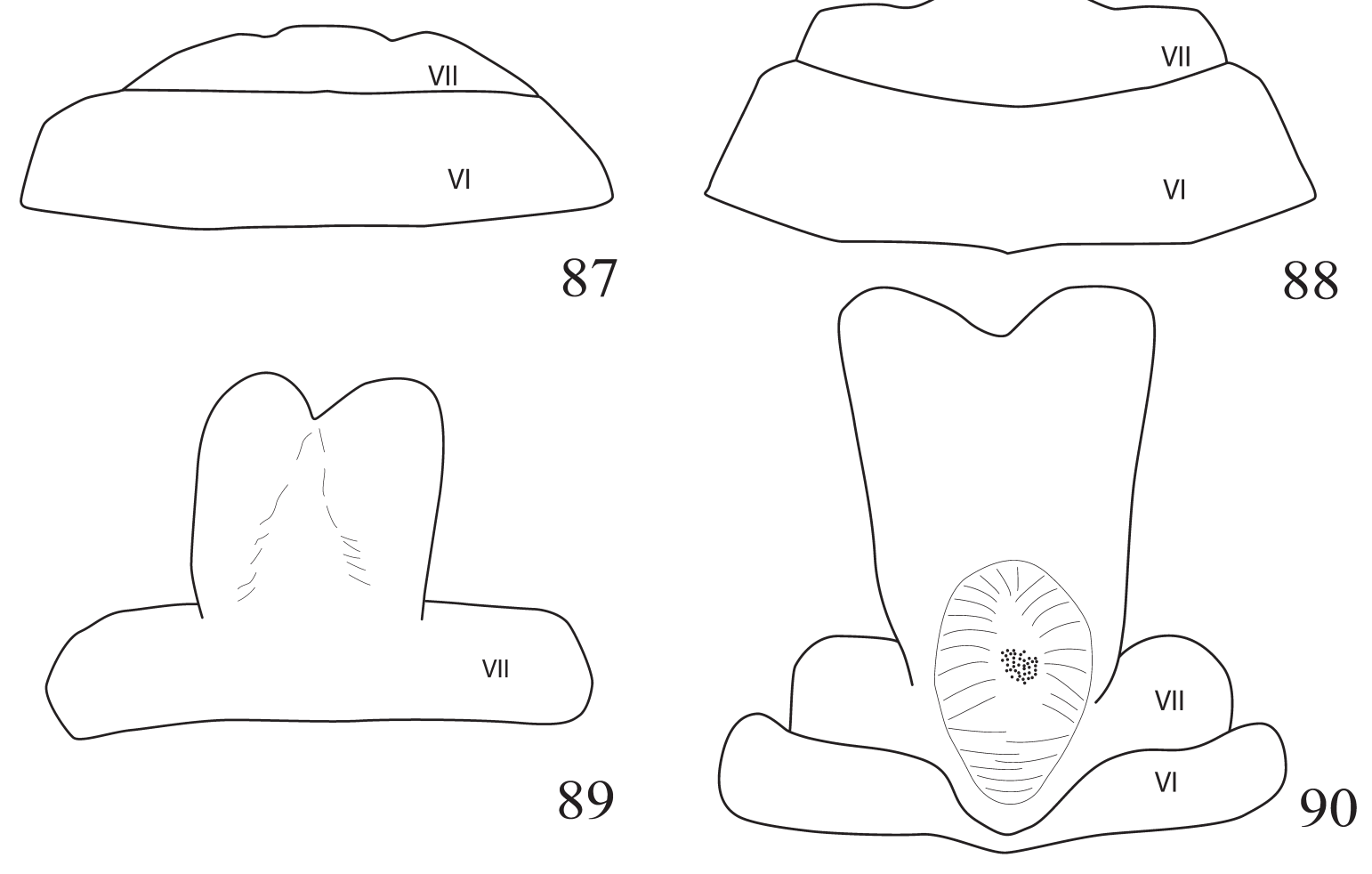

Figs 87-90. Female sternites VI and VII. 87. Elasmoscelis fuscofasciata Stål, 1854, holotype,, , drawing from dry specimen. 88. + from China, Guangxi Province, drawing from dry specimen. 89. + from Thailand, Chiangmai Province prepared in glycerin. 90. + from Thailand, $\mathrm{Na} \mathrm{Haeo}$, drawing from dry specimen. 
Genus Acothrura Melichar, 1915

Acothrura Melichar, 1915: 353.

Type species

Corethrura impunctata Jacobi, 1905. By original designation and monotypy (Melichar 1915: 353).

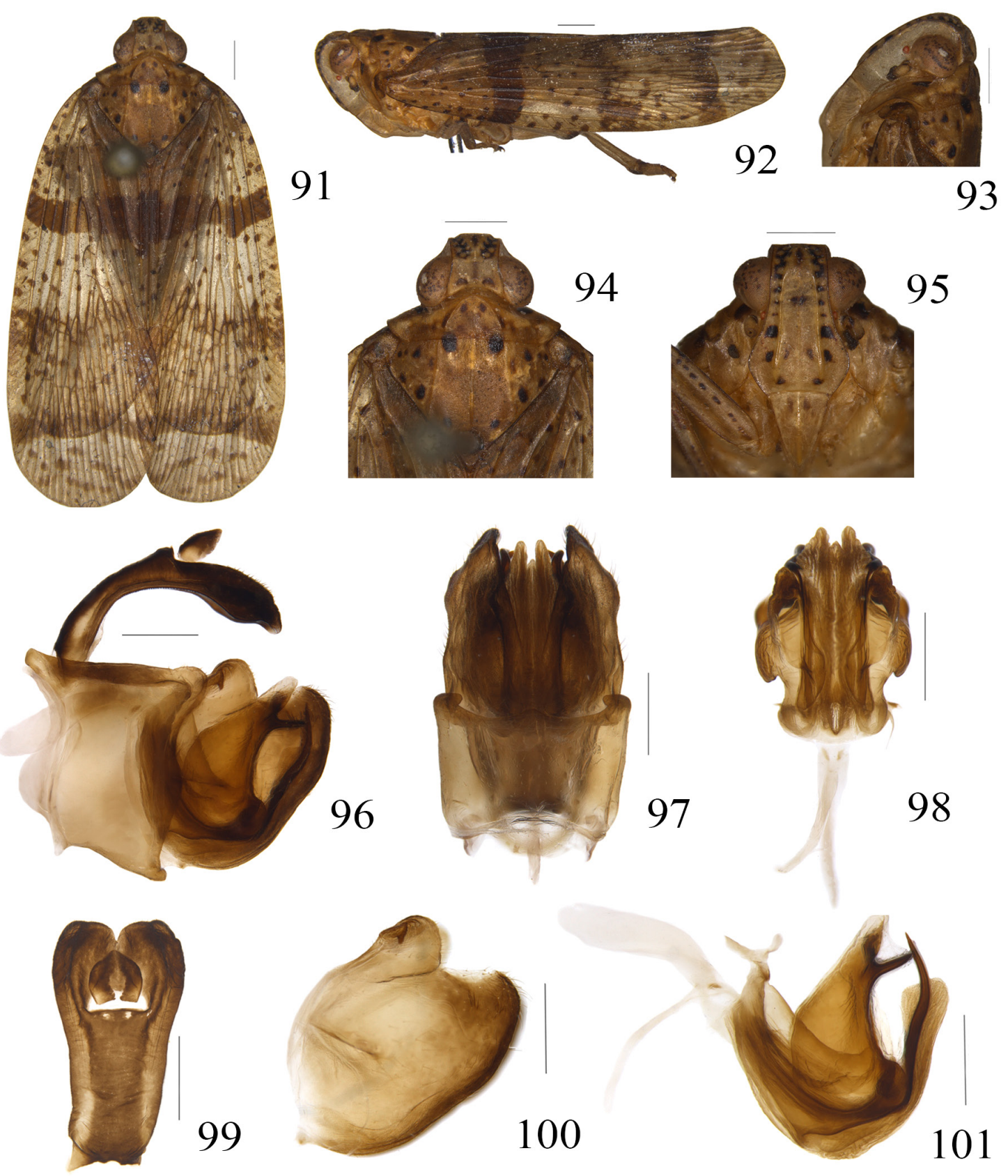

Figs 91-101. Acothrura fucizona Wang, Chou \& Yuan, 2000, paratype, ठ̂. 91. Habitus, dorsal view. 92. Habitus, lateral view. 93. Head, lateral view. 94. Head and thorax, dorsal view. 95. Frons and clypeus. 96. Male terminalia, lateral view. 97. Male terminalia, ventral view. 98. Phallic complex, ventral view. 99. Anal tube, dorsal view. 100. Gonostylus, lateral view. 101. Phallic complex and tectiform structure, lateral view. Scale bars: $91-95=1 \mathrm{~mm} ; 96-101=0.5 \mathrm{~mm}$. 
Acothrura orientalis (Liang, 2000) comb. nov.

Lacusa orientalis Liang, 2000: 289.

\section{Note}

The species Lacusa orientalis was described by Liang in 2000. Xing \& Chen (2014) reviewed all the species of the genus Lacusa. According to their observations, this species should be removed from the genus Lacusa and placed in the genera Sarebasa Distant, 1909 or Acothrura Melichar, 1915 (Xing \& Chen 2014). After comparing habitus and phallic complexes of L. orientalis (Liang 2000: figs 17, 23-27) and Acothrura fucizona Wang, Chou \& Yuan, 2000 (Figs 91-101), the very similar brown markings on vertex and thorax, shape of anal tube, pygofer with dorsal margin straight, posterior margin curved and gonostylus with apical margin concave at middle lead us to place L. orientalis in the genus Acothrura Melichar, 1915. The following new combination is accordingly proposed: Acothrura orientalis (Liang, 2000) comb. nov.

\section{Material examined}

\section{Acothrura fucizona Wang, Chou \& Yuan, 2000}

CHINA: 1 o (paratype), Xiaomengyang, Yunnan Province, 900 m, 4 Apr. 1957, coll. Shuyong Wang (NWAFU); 1 ô (paratype), Mengla, Xishuangbanna, Yunnan Province, 620-650 m, 24 May. 1959, coll. Yiran Zhang (NWAFU); 1 गे, Damenglong, Xishuangbanna, Yunnan Province, 650 m, 16 Apr. 1958, coll. Shuyong Wang (NWAFU); 1 đ, Jianghong, Yunnan Province, 1200 m, 6 Mar. 1957, coll. Bangfeiluofu (NWAFU); $1 \hat{\jmath}$, bamboo forest, Menglun, Xishuangbanna, Yunnan Province, N

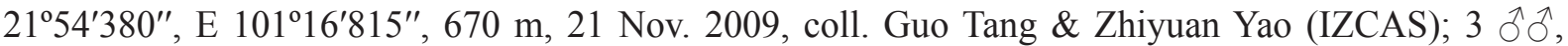

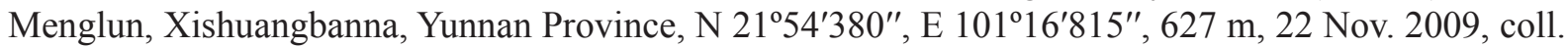
Guo Tang \& Zhiyuan Yao (IZCAS); $2 \hat{\jmath}$, bamboo forest, Menglun, Xishuangbanna, Yunnan Province, N 21 ${ }^{\circ} 54^{\prime} 380^{\prime \prime}$, E 101 $16^{\prime} 815^{\prime \prime}, 622$ m, 22 Nov. 2009, coll. Guo Tang \& Zhiyuan Yao (IZCAS); 1 ,

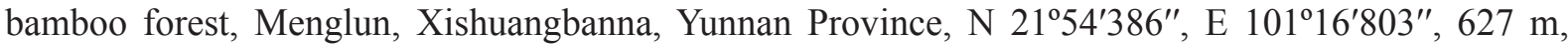
22 Nov. 2009, coll. Guo Tang \& Zhiyuan Yao (IZCAS).

VIETNAM: $1 \hat{\partial}$, Hoa-Binh, Tonkin, coll. A. de Cooman (NWAFU); $2 \hat{\jmath} \widehat{\partial}$, Hoa-Binh, Tonkin, 1919, coll. A. de. Cooman (MNHN); 2 §̋, Hoa-Binh, Tonkin, 1928, coll. A. de. Cooman (MNHN).

THAILAND: $2 \hat{\jmath}$, Chiangmni, Province Chiangdao, 450 m, 5-11 Apr. 1958, coll. T. C. Maa. (MNHN);

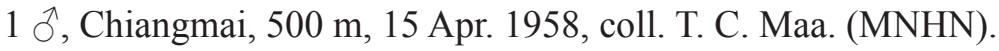

LAOS: 1 đ̊, Ban Van Eue, Vientiane Province, 30 Apr. 1966, light trap, native collector (MNHN).

\section{Acothrura impunctata (Jacobi, 1905)}

CHINA: 1 , , Mengla, Xishuangbanna, Yunnan Province, 620-650 m, 2 Jun. 1959, coll. Fuji Pu (NWAFU); 1 , Menglun, Mengla, Yunnan Province, 24 May. 1974, coll. Jiang Xiong (NWAFU); 1 , , Damenglong, Xishuangbanna, Yunnan Province, 9 Jun. 1981, coll. Huaping Lu (NWAFU); 1 , lvshilin, Menglun,

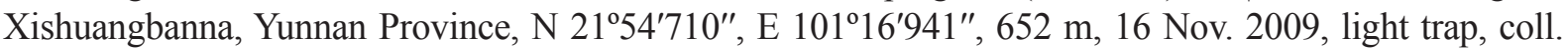

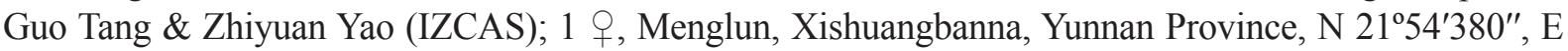
101¹6'815", 620 m, 21 Nov. 2009, light trap, coll. Guo Tang \& Zhiyuan Yao (IZCAS).

VIETNAM: 6 + , Hoa-Binh, Tonkin, 1919, coll. A. de. Cooman (MNHN).

\section{Discussion}

\section{On the collecting location and plants}

For all the new species described here, some specimens were collected in the elm green forest and/or the bamboo forest, both located near Menglun, a small town in the Mengla County, Xishuangbanna municipality of the Yunnan Province. The same locality labels could be found on material identified 
as Pitambara dawnana Distant, 1912, Acothrura fucizona Wang, Zhou \& Yuan, 2000 and Acothrura impunctata (Jacobi, 1905) from the IZCAS collections. This locality is undeniably species rich for the Lophopidae. The average annual temperature in this area is around 21 to $22^{\circ} \mathrm{C}$, with a precipitation oscillating between 1400 and 1800 millimeters. Specimens were collected between 540 and 1400 meters asl. According to the collector, the specimens caught in the bamboo forest were most likely feeding on it. No clear identification of host plant could be given for the specimens collected in the elm forest.

\section{On the genus Acothrura}

With the new combination, the genus Acothrura now counts three species: A. impunctata (Jacobi, 1905), A. fucizona Wang, Chou \& Yuan, 2000 and A. orientalis (Liang, 2000) comb. nov. We examined material from MNHN, NWAFU and IZCAS, as well as a paratype of A. fucizona (NWAFU). A. impunctata is quickly distinguishable from the other two species by its habitus and size. Jacobi (1905) described it from one specimen supposed to be a male. However, judging from the drawing the illustrated specimen is a female, easily recognisable by the shape of the anal tube, as are all the specimens examined from MNHN, NWAFU and IZCAS and identified as A. impunctata. By contrast, Liang (2000) lists only males for all specimens examined in his description of A. orientalis comb. nov. Similarly, A. fucizona is known by males only. When we looked at the distribution, we noticed that all species were present in Hoa-Binh. Specimens were collected by de Cooman. Accordingly, dimorphism cannot be excluded and it could well be possible that $A$. orientalis comb. nov. or A. fucizona represent a synonym of $A$. impuctata. The only way to verify this hypothesis would be to find specimens in copula or to make barcoding analysis for the three species.

\section{Acknowledgements}

We want to express our gratitude to Gunvi Lindberg from the SMNH who lent us the holotype of L. fuscofasciata. We are grateful to the IZCAS and NAU for the loan of specimens. Our thanks go as well to Laurent Fauvre, from the MNHN for taking some pictures of the specimens. This study was supported by the National Natural Science Foundation of China (31372234), the Pilot Project of Standardized Curation, Data Integration and Resource Sharing of Zoological Collections (2005DKA21402) by the Ministry of Science and Technology of China, and China Scholarship Council (201406300104).

\section{References}

Bourgoin, T. 1988. Anew interpretation of the homologies in the Hemiptera male genitalia, illustrated by the Tettigometridae (Hemiptera: Fulgoromorpha). In: Carlo Vidano C. \& Arzone A. (eds) 6th Auchenorrhyncha Meeting, Turin (Italie), 1987, Proceedings: 113-120. Consiglio Nazionale delle Richerche.

Bourgoin T. 2016. FLOW (Fulgoromorpha Lists On the Web): a world knowledge base dedicated to Fulgoromorpha. Version 8, updated [14 Mar. 2016]. Available from: http://hemiptera-databases.org/ flow/ [accessed 14 Mar. 2016]

Bourgoin T., Wang R.R., Asche M., Hoch H., Soulier-Perkins A., Stroiński A., Yap S. \& Szwedo J. 2015. From micropterism to hyperpterism: recognition strategy and standardized homology-driven terminology of the forewing venation patterns in planthoppers (Hemiptera: Fulgoromorpha). Zoomorphology 134 (1): 63-77. http://dx.doi.org/10.1007/s00435-014-0243-6

Chou I., Lu J.S., Huang J. \& Wang S.Z. 1985. Economic Insect Fauna of China. Fasc. 36. Homoptera: Fulgoroidea. Science Press, Beijing.

Distant W.L. 1906. The fauna of British India, including Ceylon and Burma. Rynchoptera. Vol. 3. Heteroptera-Homoptera. Taylor \& Francis, London.

Emeljanov A.F. 2014. On the subdivision of the family Lophopidae (Homoptera, Auchenorrhyncha: Fulgoroidea) on the subfamilies and tribes with description of two new tribes. Entomological Review 94 (2): 208-210. http://dx.doi.org/10.1134/S0013873814020080 
Jacobi A. 1905. Zur Kenntnis der Cicadenfauna von Tonking. Zoologische Jahrbücher Abteilung für Systematik, Geographie und Biologie der Thiere 21: 425-446.

Liang A.P. 1996. Taxonomic changes in Chinese Lophopidae with a check list of Chinese species (Homoptera: Fulgoroidea). Pan-Pacific Entomologist 72 (3): 145-151.

Liang A.P. 1997. Sugarcane and rice planthoppers of the genus Pyrilla Stål in southern China (Insecta: Homoptera: Auchenorrhyncha: Lophopidae). Reichenbachia 32 (7): 33-39.

Liang A.P. 2000. Oriental Lophopidae: new taxa and taxonomic changes (Insecta: Hemiptera: Auchenorrhyncha: Fulgoroidea). Reichenbachia 33 (35): 281-311.

Melichar L. 1915. Monographie der Lophopinen. Annales Historico-Naturales Musei Nationalis Hungarici 13: 337-385.

Stål C. 1854. Nya Hemiptera. Ofversigt af Kongliga Svenska Vetenskaps-Akademiens Förhandlingar 11: $231-255$.

Stål C. 1862. Novae vel minus cognitae Homopterorum formae et species. Berliner Entomologische Zeitschrift 6: 303-315.

Soulier-Perkins A. 1998. The Lophopidae (Hemiptera: Fulgoromorpha): Description of three new genera and key to the genera of the family. European Journal of Entomology 95: 599-618.

Soulier-Perkins A. 2000. A phylogenetic and geotectonic scenario to explain biogeography of the Lophopidae (Hemiptera, Fulgoromorpha). Palaeogeography, Palaeoclimatology, Palaeoecology 160 (3-4): 239-254. http://dx.doi.org/10.1016/S0031-0182(00)00071-7

Soulier-Perkins A. 2001. The phylogeny of the Lophopidae and the impact of sexual selection and coevolutionary sexual conflict. Cladistics 17: 56-78. http://dx.doi.org/10.1111/j.1096-0031.2001.tb00111.x

Walker F. 1857. Catalogue of the Homopterous insects collected at Sarawak, Borneo, by Mr. A. R. Wallace, with descriptions of new species. Journal of the Proceedings of the Linnean Society of London 1 (4): 141-175. http://dx.doi.org/10.1111/j.1096-3642.1857.tb00966.x

Wang Y.L., Chou I. \& Yuan F. 2000. Descriptions of a new record genus and species and a new species of Lophopidae (Homoptera: Fulgoroidea) from China. Entomotaxonomia 22 (4): 242-246.

Wang M.L. \& Wang Y.L. 2012. First record of the genus Podoschtroumpfa (Hemiptera: Lophopidae) from China with a redescription of one newly recorded species. Entomotaxonomia 34 (4): 629-632.

Xing J.C. \& Chen X.S. 2014. Taxonomic study of the planthopper genus Lacusa Stål, 1862 (Hemiptera, Fulgoromorpha, Lophopidae). ZooKeys 405: 139-148. http://dx.doi.org/10.3897/zookeys.405.6981

Manuscript received: 23 June 2015

Manuscript accepted: 19 November 2015

Published on: 30 March 2016

Topic editor: Koen Martens

Desk editor: Charlotte Thionois

Printed versions of all papers are also deposited in the libraries of the institutes that are members of the EJT consortium: Muséum national d'Histoire naturelle, Paris, France; Botanic Garden Meise, Belgium; Royal Museum for Central Africa, Tervuren, Belgium; Natural History Museum, London, United Kingdom; Royal Belgian Institute of Natural Sciences, Brussels, Belgium; Natural History Museum of Denmark, Copenhagen, Denmark. 